Boise State University

ScholarWorks

$10-2002$

Hierarchical Geostatistics and Multifacies Systems: Boise Hydrogeophysical Research Site, Boise, Idaho

Warren Barrash

Boise State University

Tom Clemo

Boise State University 


\title{
Hierarchical geostatistics and multifacies systems: Boise Hydrogeophysical Research Site, Boise, Idaho
}

\author{
Warren Barrash and Tom Clemo \\ Center for Geophysical Investigation of the Shallow Subsurface and Department of Geosciences, Boise State University, \\ Boise, Idaho, USA
}

Received 7 May 2002; accepted 24 May 2002; published 17 October 2002.

[1] The geostatistical structure of a heterogeneous coarse fluvial aquifer is investigated with porosity data derived from neutron logs at a research well field (Boise Hydrogeophysical Research Site, or BHRS) that was designed, in part, to support threedimensional geostatistical analysis of hydrologic and geophysical parameters.

Recognizing that the coarse fluvial deposits include subdivisions (units between bounding surfaces), we adopt a hierarchical approach and examine the porosity geostatistics of the aquifer at three scales. At the BHRS, the saturated fluvial deposits as a whole (maximum interwell spacing $\sim 80 \mathrm{~m}$, thickness $\sim 16-18 \mathrm{~m}$ ) are at hierarchical level 1; five subhorizontal units within these deposits (four cobble-dominated units and a channel sand) can be traced across the central area of the BHRS and are at hierarchical level 2; and subunits (patches or lenses) in one of the level 2 units (Unit 4), are at hierarchical level 3. We use variography and porosity statistics to recognize nonstationarity at hierarchical level 1 and in one of the level 2 units (Unit 4) where the means and variances of porosity differences as a function of lag are not constant between distinct units and subunits, respectively. The geostatistical structure at level 1 is modeled with different horizontal and vertical structures that have different sills (vertical sill greater than horizontal sill). The difference in sills can be explained quantitatively by the summing of weighted sills from all individual units and combined units (i.e., a given pair of different units), where the weights are the proportions of data pairs contributing to the sills at each lag from the individual and combined units. Extension of this analysis leads to a weighted, multistructure form of the variogram function whereby a global experimental variogram in a hierarchical system can be decomposed quantitatively into weighted component individual- and combined-unit (or facies) structures for any number of units or hierarchical levels. Such decomposition of the global horizontal variogram from the BHRS indicates that short-range periodicity in that structure is due to both (1) combined-unit structures associated with patches or lenses at hierarchical level 3 in Unit 4 and (2) variations in thickness of Unit 2. For hierarchical multifacies systems, structure models fit to global horizontal and vertical experimental variograms may not be useful for subsequent stochastic modeling if the system on which the structure models are based is nonstationary. INDEX TERMS: 1829 Hydrology: Groundwater hydrology; 1869 Hydrology: Stochastic processes; 5114 Physical Properties of Rocks: Permeability and porosity; KEYWORDS: Geostatistics, Porosity, Heterogeneity

Citation: Barrash, W., and T. Clemo, Hierarchical geostatistics and multifacies systems: Boise Hydrogeophysical Research Site, Boise, Idaho, Water Resour. Res., 38(10), 1196, doi:10.1029/2002WR001436, 2002.

\section{Introduction}

[2] In this paper, we examine the geostatistical structure of porosity in a heterogeneous aquifer comprised of coarse fluvial deposits. In particular, we use porosity values based on neutron log measurements taken in wells at the Boise Hydrogeophysical Research Site (BHRS) (Figure 1), a research well field designed, in part, to capture threedimensional distributions of geologic, hydrologic, and geophysical parameters [Barrash and Knoll, 1998]. We adopt a

Copyright 2002 by the American Geophysical Union. 0043-1397/02/2002WR001436\$09.00 hierarchical (multiscale) approach to analyzing the geostatistics of the porosity data from this site.

[3] The hierarchical approach is similar to the concept of architectural elements in sedimentary systems [Miall, 1985] where units with recognizable erosion-surface boundaries occur at successive size scales (i.e., assemblages of sedimentary facies, facies, subfacies). In such a system, there is less variability within than between facies because facies represent similar depositional processes and environments that produce similar products [Anderson, 1989; Davis et al., 1993, 1997; Koltermann and Gorelick, 1996]. Field and modeling studies have demonstrated the value of relating distributions of hydrologic parameters to sedimentary facies [Poeter and Gaylord, 1990; Webb and 


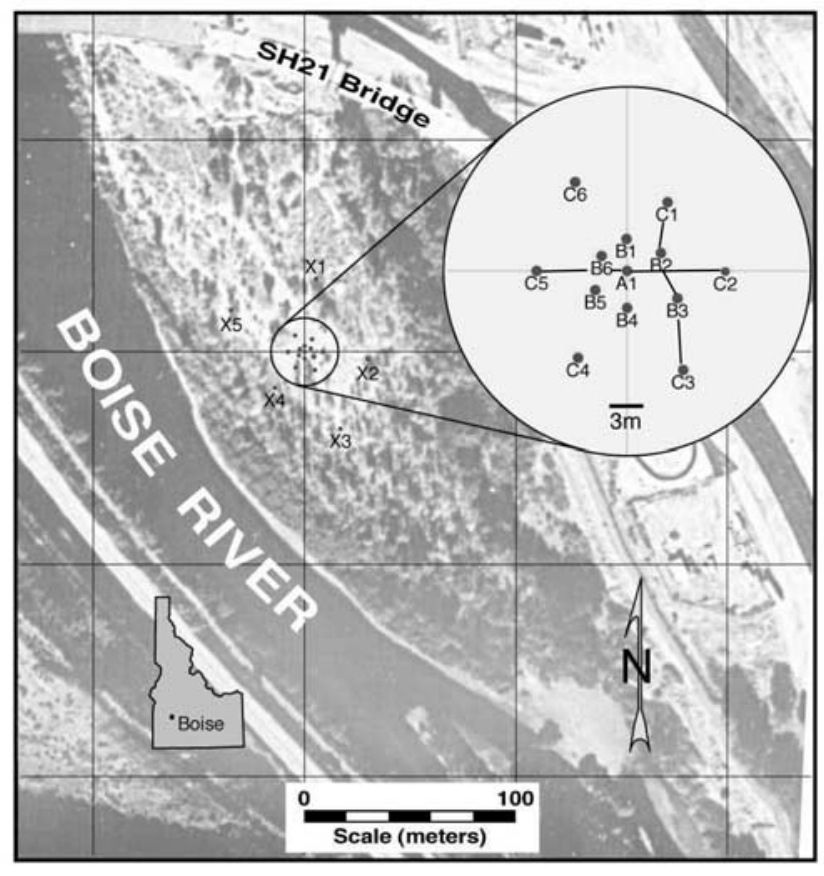

Figure 1. Photomap of the BHRS on a cobble bar adjacent to the Boise River showing boundary wells (X-series wells) and detailed map of central area wells (A1, and B- and Cseries wells in double-ring design) in highlighted area. Boise River flows generally northward through its canyon in this reach. Traces of cross-sections (see Figures $4 \mathrm{a}$ and 4b) are shown in approximate river-parallel (C1-B2-B3-C3) and cross-river (C5-A1-C2) orientations.

Anderson, 1996; Allen-King et al., 1998; Fogg et al., 1998]. Also, geostatistical characteristics of individual facies have been identified within larger-scale sedimentary deposits. Daws and Prosser [1992] fit spherical structures to four different facies in the Brent Group petroleum reservoir based on closely spaced gas minipermeameter measurements on core, and identified hierarchical levels of sedimentary architecture controlling permeability heterogeneity. Jussel et al. [1994] determined geostatistical structures and length scales for permeability of facies in coarse glacio-fluvial deposits in quarries in Switzerland. Similarly, Davis et al. [1993, 1997] determined geostatistical structures and length scales for air permeability of facies in fluvial deposits exposed in outcrops in the Rio Grande valley. Rea and Knight [1998] determined geostatistical structure of facies at outcrops of deltaic sediments based on ground-penetrating radar (GPR) reflection data as proxy data for hydrogeologic parameters.

[4] Multifacies and hierarchical systems may exhibit complex geostatistical structure [Journel and Huijbregts, 1978; Prosser et al., 1995; Kupfersberger and Deutsch, 1999] due to different geostatistical structures and scales associated with different facies in the same investigated volume, and to different structures and scales in different directions (anisotropy). In this paper we use the hierarchical approach as the basis for: (1) characterizing geostatistical structure in the subsurface coarse fluvial deposits at the BHRS at three scales or hierarchical levels; (2) demonstrating the cause for inconsistent horizontal and vertical sills for the fluvial aquifer as a whole (level 1); and (3) quantitatively determining the composition of experimental variograms in multifacies and multiscale systems.

\subsection{Terminology}

[5] We refer to stratigraphic subdivisions at the BHRS in the generic sense as units rather than facies because identification of such subdivisions with specific sedimentary environments from drill core is difficult in very coarse (e.g., cobble-dominated) unconsolidated subsurface deposits. However, we use the term facies where we discuss a repeated type of unit at the BHRS (i.e., where a type of facies is indicated by porosity statistics and geostatistics) or repeated types of sedimentary deposits in general. For the purposes of this paper, the sitewide assemblage of coarse fluvial deposits at the BHRS is the highest hierarchical level (level 1), units within these deposits are at hierarchical level 2 , and subunits (patches or lenses) within the level 2 units are at hierarchical level 3. Also, for simplicity, we refer to semivariograms as variograms.

\section{Boise Hydrogeophysical Research Site}

[6] The Boise Hydrogeophysical Research Site is located on a gravel bar adjacent to the Boise River $\sim 15 \mathrm{~km}$ from downtown Boise, Idaho (Figure 1). The shallow aquifer at the BHRS consists of late Quaternary, coarse (dominantly cobble-and-sand), fluvial deposits. Saturated thickness of this aquifer ranges between $\sim 16$ and $18 \mathrm{~m}$ depending on seasonal variation in river stage and local depth to a tight red clay that underlies the site. The well field consists of 13 wells in the central area $(\sim 20 \mathrm{~m}$ diameter $)$ and five boundary wells about $10-35 \mathrm{~m}$ from the central area (Figure 1). The general design of the 13 central area wells is two concentric rings of six wells each around a central well. This design, and the construction of individual wells, support a wide variety of single-well, cross-well, and multiple-well hydrologic and geophysical tests for thorough three-dimensional characterization of the central area [Barrash et al., 1999; Clement et al., 1999]. In addition, to support geostatistical analysis of parameters measured at wells in the central area of the BHRS, locations of the 13 wells in the concentric ring design were selected to have similar numbers of, and similar azimuthal distributions of, well pairs at $1 \mathrm{~m}$ lag increments through the expected range of the permeability variogram [Barrash and Knoll, 1998].

\section{Porosity at the BHRS}

[7] Porosity values are available from the coarse fluvial aquifer based on the following petrophysical transform of neutron well-log measurements [Hearst and Nelson, 1985]:

$$
\begin{gathered}
N=A+B(\log \phi) \\
\phi=10^{(N-A) / B}
\end{gathered}
$$

where $N$ is the count rate for the location of interest; $A$ and $B$ are count rates for known or estimated porosity values in the deposits of interest below the water table; and $\phi$ is porosity. The porosity data set consists of 4699 values at $0.06 \mathrm{~m}$ depth increments below the water table in the cobble-andsand deposits in the 18 wells at the BHRS. The $\mathrm{x}, \mathrm{y}$, and $\mathrm{z}$ 


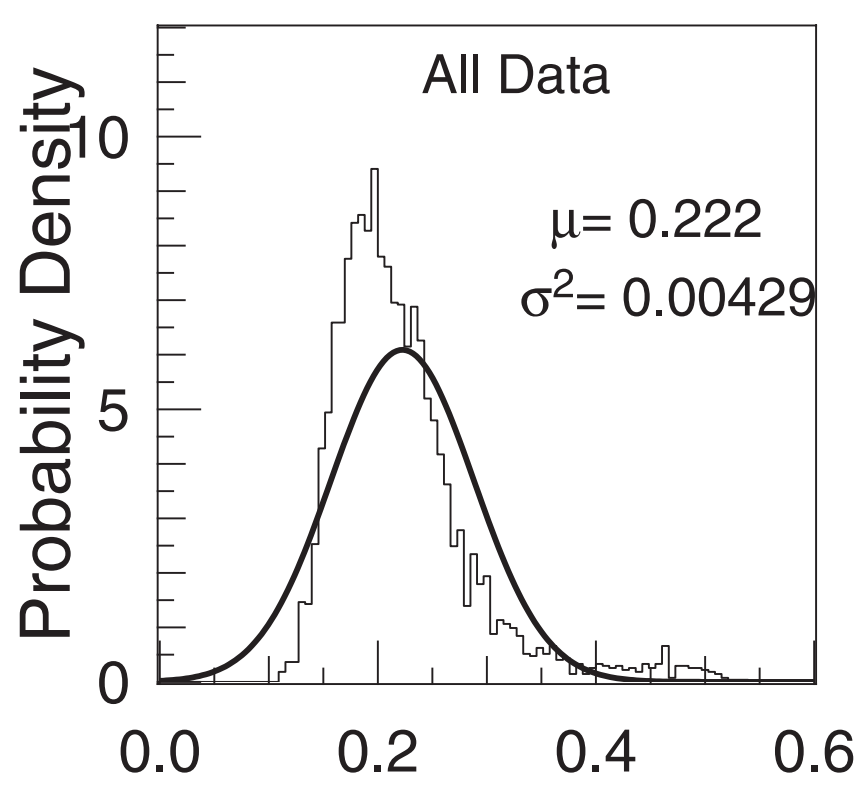

\section{Porosity}

Figure 2. Probability density functions for all porosity values in the fluvial aquifer at the BHRS. A normal distribution with the same mean and variance is superimposed.

positions for each measurement are tied to surveyed reference points at wells and are adjusted with data from deviation logs. For the statistical and geostatistical analyses in this paper, we assume that each porosity value is an independent measurement assignable to a point.

[8] Sources of noise in the porosity data are limited because (1) all wells were constructed with the driven-casing method to minimize formation disturbance [Morin et al., 1988; Barrash and Knoll, 1998]; (2) primary or secondary clay minerals are rare [Reboulet and Barrash, 1999, 2000]; (3) sediments are derived largely from similar (granitic) source rock so composition of fluvial deposits varies little [Barrash et al., 1997]; and (4) the deposits are unaltered, uncemented, and uncompacted. Reproducibility of neutron logs was checked; correlation coefficients ranged from 0.935 to 0.966 for the six log pairs from four logging runs in well C5.

[9] High and low porosity values are taken to be 0.50 and 0.12 , respectively, based on data from published literature on loose sands and on tight cobbles and sands. Verification of neutron-derived porosity values against core at the BHRS is only possible in a general sense because, although core recovery was $83 \%$ below the water table and sand matrix was recovered with adjacent cobbles, grain-to-grain positioning was not preserved [Barrash et al., 1999]. For perspective on the high end of the range of porosity values, a number of workers report porosities $\geq 0.50$ in fluvial sand deposits [e.g., Pettijohn et al., 1973; Atkins and McBride, 1992] including deposits similar to those at the BHRS [Jussel, 1989]. Grain-size distribution (GSD) data indicate that sand core samples from the BHRS are very well sorted with minimal silt and clay [Reboulet and Barrash, 2000]. As a first-order independent check on porosity values from neutron $\operatorname{logs}$, the porosity logs generated from single-well
GPR velocity profiles at this site return porosity values only a few percentage points lower than the neutron-derived logs in the highest-porosity sand [Knoll and Clement, 1999].

[10] For perspective on the low end of the range of porosity values, Jussel et al. [1994] found an average porosity value of 0.14 and a low value of 0.11 for the lowest porosity cobble-and-sand facies in similar deposits in Switzerland. Also, low-porosity values estimated from single-well GPR profiles are comparable to the neutronderived logs in the low-porosity cobble-dominated units at the BHRS [Knoll and Clement, 1999]. The low-porosity value of 0.12 would be equivalent to a fractional packing model [Koltermann and Gorelick, 1995] with 0.30 porosity for a cobble framework that had sand matrix infill with 0.40 porosity. Primary or secondary clay minerals are rare in these deposits and so should not affect the accuracy of the petrophysical transforms used to estimate porosity values from neutron logs or GPR profiles.

[11] The probability density function (pdf) for all cobbleand-sand porosity data derived from neutron logs is shown in Figure 2. These data for the deposits as a whole deviate from a normal distribution by having both a high-porosity tail and also a low-amplitude high-porosity mode.

\section{Stratigraphy}

[12] In many subsurface environments, facies can be recognized by inspection of core. However, in very coarsegrained sedimentary environments (Figure 3), such as the cobble-and-sand deposits at the BHRS (where the diameters of framework clasts commonly exceed the 6-cm ID of the core barrel), recognition of facies or units in the subsurface is less direct [e.g., Huggenberger, 1993; Barrash and Morin, 1997; Regli et al., 2002]. Using a combination of geologic, geophysical, and hydrologic information, the subsurface fluvial deposits are subdivided into five units in the central area of the site where well control is greatest (Figure 1).

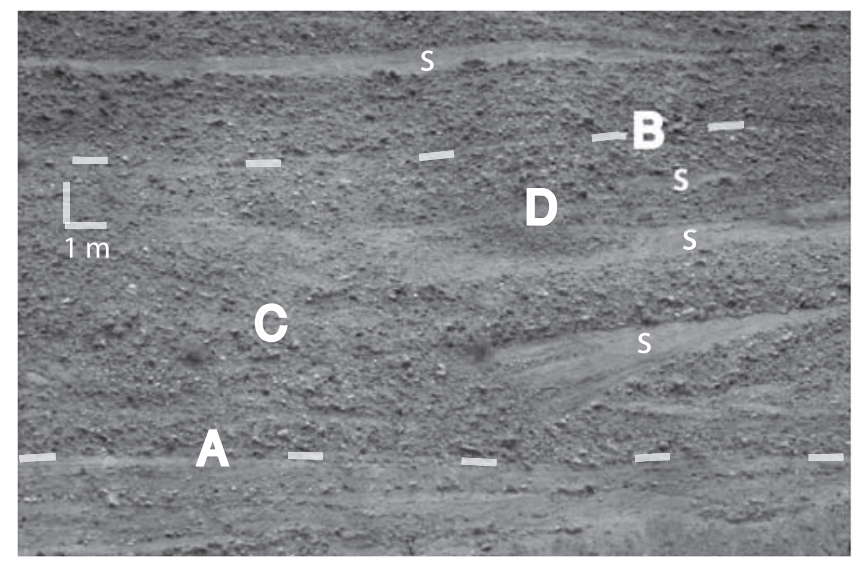

Figure 3. Photograph of coarse fluvial deposits in road cut $2.5 \mathrm{~km}$ upriver from the BHRS. Laterally persistent bounding surfaces (A and B) can be identified in addition to both gradual (e.g., C) and abrupt (e.g, D) changes of sedimentary structure and texture within the unit between bounding surfaces A and B. Note predominance of cobblesize framework clasts overall, but also the presence of distributed sand bodies (s), and the sand-dominated unit below bounding surface $\mathrm{A}$. 
These units are: four subhorizontal cobble-dominated units and a sand unit which cuts into the uppermost cobbledominated unit in the western half of the BHRS. No silt or clay lenses or layers have been intercepted in wells at the BHRS, nor have they been observed in exposures of similar deposits in nearby outcrops (e.g., Figure 3).

[13] The sand unit has been recognized directly in core. Subdivision of the remaining cobble-dominated section into four units follows from examination of wire line logs, GPR reflection imagery, seismic velocity profiles, and porosity pdfs for the units. Recent studies [e.g., McKenna and Poeter, 1995; Hyndman and Gorelick, 1996; Hubbard et al., 1999] have demonstrated that these and similar methods are useful for subdividing shallow subsurface sedimentary deposits into facies or units, including coarse fluvial deposits similar to those in the Boise valley [e.g., Huggenberger et al., 1994; Asprion and Aigner, 1997; Beres et al., 1999].

[14] Figure 4 gives examples of the indirect evidence used to subdivide the coarse fluvial deposits into five level 2 units. Figures $4 \mathrm{a}$ and $4 \mathrm{~b}$ are cross-sections of porosity logs through the central area. In the cobble-dominated section (Units 1-4), bounding surfaces are located at changes from relatively low porosity sediments (Units 1 and 3 ) to relatively higher and more-variable porosity sediments (Units 2 and 4). The sand is Unit 5 which has high porosity and pinches out between wells C5 and A1. Figure 4c shows an example vertical seismic ( $\mathrm{SH}$-wave) profile for well $\mathrm{C} 3$ which is included in the porosity log profile of Figure $4 \mathrm{a}$. Changes in SH-wave velocity (i.e., changes in slope in Figure 4c) occur at or near the bounding surfaces shown in the porosity log cross-section.

[15] Stratigraphic units interpreted from GPR reflection data (Figure 4d) correspond approximately with units in porosity logs (compare with Figure 4b). Continuous reflectors (dashed lines in Figure 4d) are bounding surfaces between regions with different reflection and diffraction patterns [e.g., Beres et al., 1999; Peretti et al., 1999]. Bounding surface locations differ in detail between the porosity logs and the GPR reflection section (Figures 4b and $4 \mathrm{~d}$ ); this is not unexpected considering resolution differences, differences in what the methods are sensing in the deposits, uncertainty in the depths of radar reflectors (a function of radar velocity), and uncertainty in placement of contacts in porosity logs.

[16] Porosity pdfs provide additional support for the unit selections interpreted from porosity logs. Adjacent units have quite different porosity pdfs based on observation and descriptive statistics (Figure 5), and statistical tests for equality of population distributions and variances (Table 1). Use of porosity and/or permeability population statistics as evidence for differences between sedimentary units is supported by recent studies where visual observations from core, quarry, or outcrop provide a priori evidence of facies association, and where parameter populations in adjacent facies are distinct [e.g., Goggin et al., 1988; Davis et al., 1993, 1997], including studies in coarse fluvial deposits similar to those at the BHRS [Jussel, 1989; Jussel et al., 1994]. However, lacking trenches, identification of cobble-dominated units at the BHRS with sedimentary facies is uncertain at this time.

[17] Here we note the strong similarity in pdf means and variances for Units 1 and 3 (Figure 5), and consider whether these two units should be interpreted as a type of deposit or facies that is repeated, or as two different facies with some coincidental similarities. Statistically, porosity populations of Units 1 and 3 fail the Kolmogorov-Smirnov test for equality of distributions and fail the $t$ test for equality of means, although the null hypothesis of equal variances cannot be rejected at a $p$ value of 0.083 (Table 1) with Levene's test [Milliken and Johnson, 1992]. Indeed, sample numbers are large (Figure 5) and the porosity pdfs of Units 1 and 3 are similar but not identical. However, units need not be identical to be the same facies. We revisit the subject of grouping units into facies in section 6.1.

\section{Hierarchical Porosity Geostatistics}

[18] In this section we generate experimental horizontal and/or vertical variograms at successive hierarchical levels, fit the experimental variograms with geostatistical structure models, and consider whether the parameter distributions violate the conditions of second-order stationarity under the intrinsic hypothesis [Journel and Huijbregts, 1978].

\subsection{Method of Geostatistical Analysis}

[19] To calculate experimental variograms for porosity, we use the classical geostatistical estimator [Journel and Huijbregts, 1978]:

$$
\gamma(h)=\frac{1}{2 N} \sum_{i=1}^{N}\{z(x)-z(x+h)\}^{2}
$$

where $z$ is the measured value of the parameter of interest; $x$ is the initial point of a data pair; $h$ is the lag vector separating the data pair; and $N$ is the number of data pairs in lag $h$. Experimental variograms are generated for lags to full separation distances, but only values to one half of the full separation distance for a given distribution are used in fitting an experimental variogram to a geostatistical model structure [Journel and Huijbregts, 1978]. In this paper, we restrict our analysis to "point" measurement data.

[20] For perspective on the uncertainty of variogram values, we use the jackknife method [Shafer and Varljen, 1990; Davis et al., 1997] to add approximate jackknife confidence intervals (JKCI) of $2 \sigma$ on variogram values. Also, reciprocals of the $2 \sigma \mathrm{JKCI}$ values are used as weights in fitting experimental variograms to transition, periodic, and/or nested geostatistical structure models with a weighted nonlinear least squares technique [National Institute of Standards and Techonology (NIST), 1998]. In this model-fitting process, a nugget was included initially as part of the geostatistical structure that was fit to a given experimental variogram. However, if the magnitude of the nugget was not different from zero with $95 \%$ confidence, then the nugget component was removed from the model and the model was refit to the experimental variogram.

[21] We have checked for possible differences in fitted model structures due to distortions associated with deviations from normality in the porosity pdfs used in generating the experimental variograms. Although normality is not required for geostatistical analysis, it is often assumed and deviations from normality may result in experimental variograms that are distorted and thereby more difficult to model [Armstrong, 1984; Dowd, 1984]. Here we note that models fit to variograms generated with the Cressie-Hawkins variogram estimator [Cressie and Hawkins, 1980; Woodbury and 

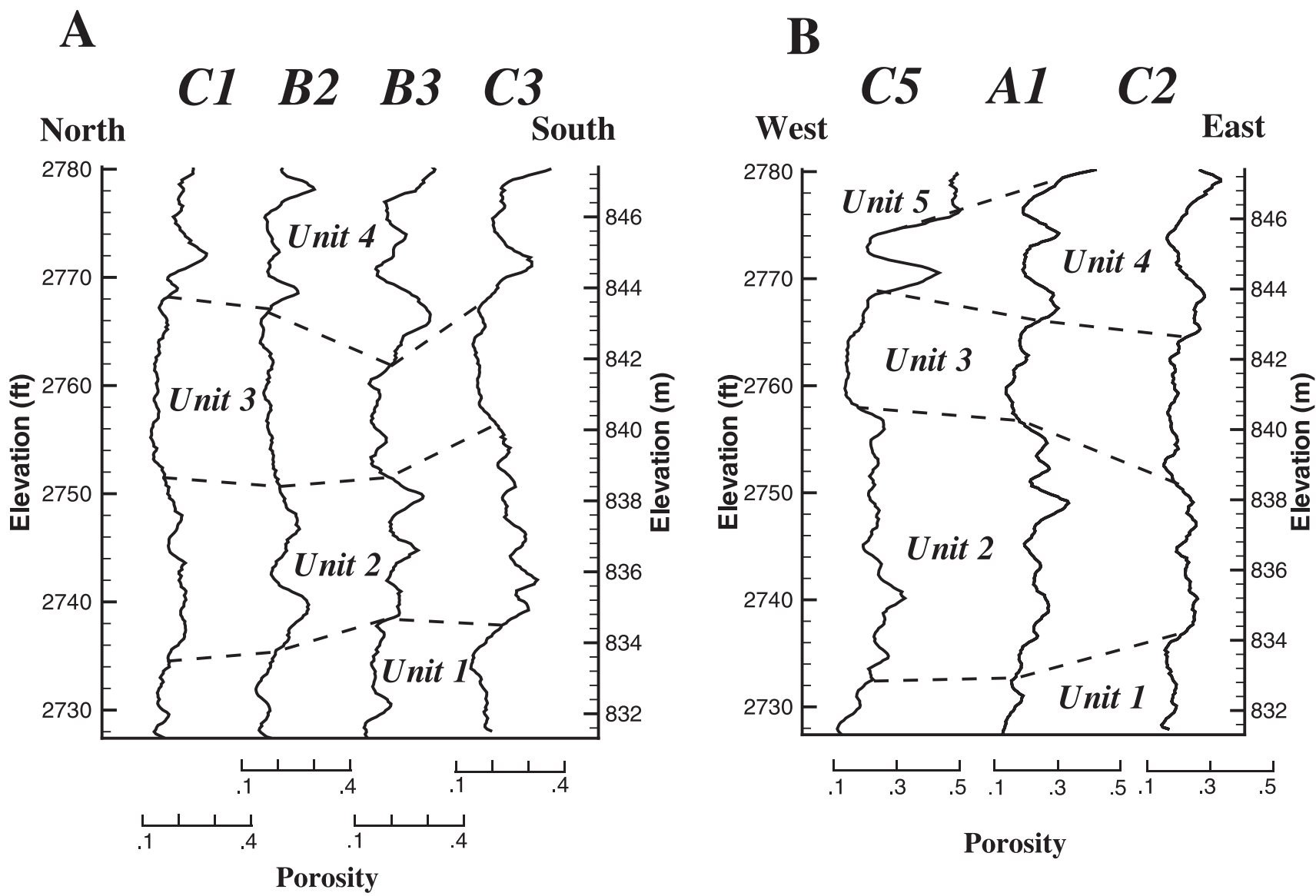

Porosity
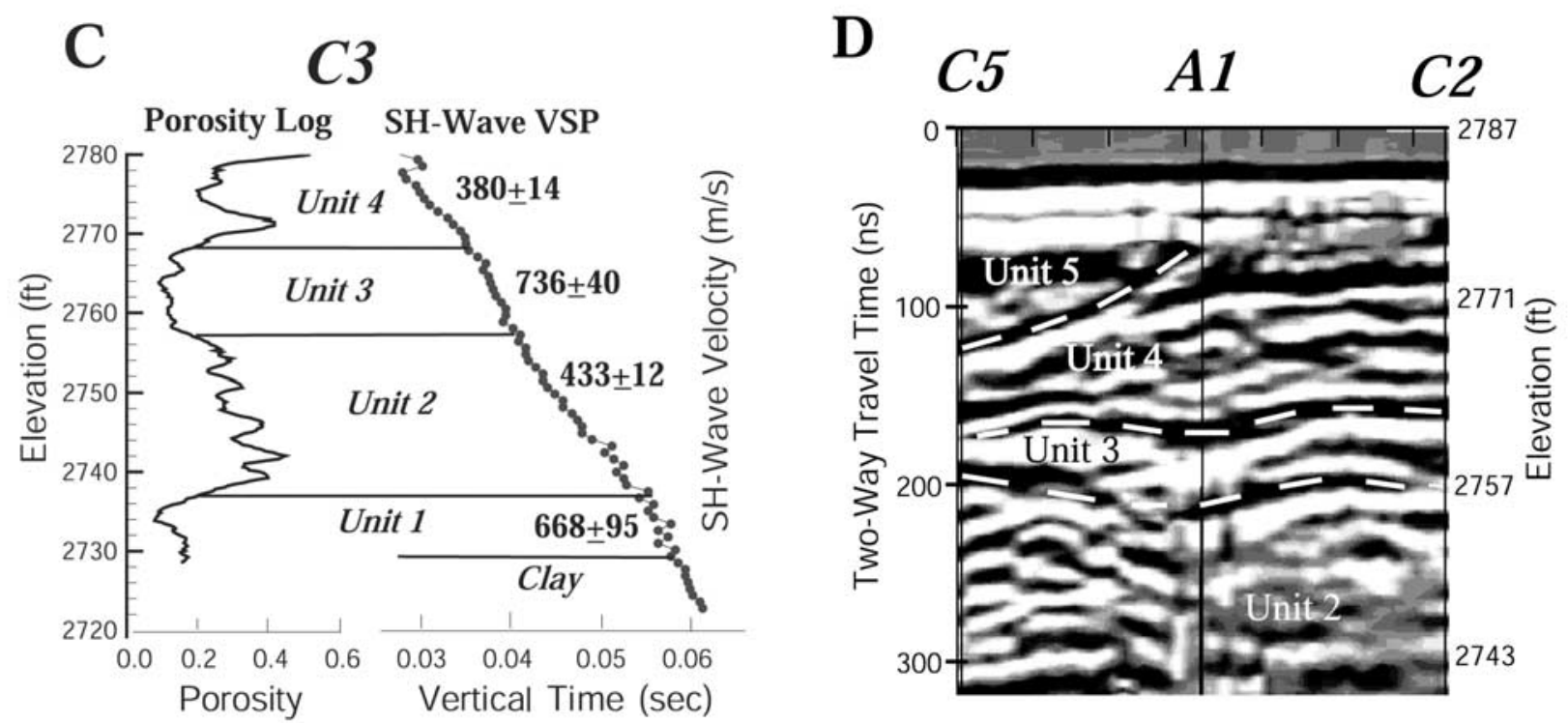

Figure 4. Indirect evidence supporting stratigraphy in the fluvial aquifer at the BHRS. (A) Porosity logs from water table to base of fluvial deposits. Orientation is in general direction of river flow; relative horizontal well positions not to scale (see inset location map in Figure 1). Units 1-4 are cobble-dominated units; Unit 5 is channel sand. (B) Porosity logs from water table to base of fluvial deposits. Orientation is perpendicular to general direction of river flow (Figure 1). Channel sand thickens toward river and pinches out near center of well field. (C) Porosity log and vertical SH-wave seismic profile at well C3 with SH-wave velocities grouped by porosity unit. Vertical times are $\mathrm{SH}$-wave first arrival times projected to vertical. Data courtesy of Dr. Paul Michaels. (D) GPR reflection profile (50 MHz antenna frequency) in cross-river orientation for comparison with porosity logs in (B). Dashed lines trace boundaries which separate regions (generally corresponding to porosity units) with different reflection character. Vertical elevation scale is not uniform because of radar velocity variation, which also correlates with porosity [Knoll and Clement, 1999]. Data courtesy of William Peretti. 


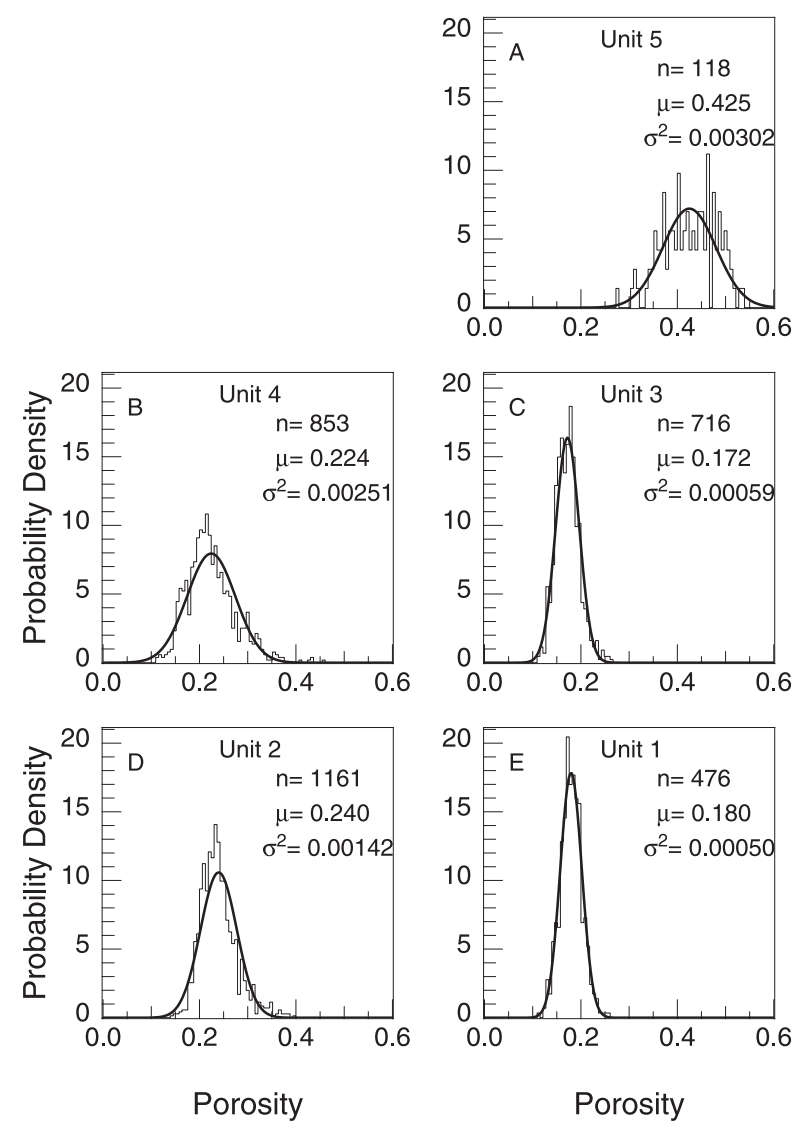

Figure 5. Probability density functions for porosity values in level 2 units in the central area of the BHRS. Normal distributions with the same means and variances, respectively, are superimposed. (A) Unit 5. (B) Unit 4. (C) Unit 3. (D) Unit 2. (E) Unit 1.

Sudicky, 1991] are the same as those generated with the classical variogram estimator in structural type for most analyses (see below and cf. Barrash and Clemo [2000]), and have the same relative magnitudes of geostatistical structure parameter values for all analyses. However, only experimental variograms generated with the classical estimator are used in this paper.

[22] Random functions that are second-order stationary have constant means and variances throughout the region of investigation. As is common in geostatistical analysis, we invoke the intrinsic hypothesis whereby first-order differences between parameter values at separation distances have zero mean and constant variance [Journel and Huijbregts, 1978, p. 33]:

$$
\begin{gathered}
E\{Z(x)\}=m, \forall x ; \\
\operatorname{Var}\{Z(x+h)-Z(x)\}=E\left\{[Z(x+h)-Z(x)]^{2}\right\}=2 \gamma(h), \forall x
\end{gathered}
$$

where $Z(x)$ is a random variable and $m$ is the expected value or the mean. We use these conditions for evaluating nonstationarity in this paper.

\subsection{Porosity Geostatistics of Hierarchical Level 1}

[23] Geostatistical analyses based on measurement data in shallow fluvial aquifers commonly treat an aquifer as a whole [Woodbury and Sudicky, 1991; Rehfeldt et al., 1992; Indelman et al., 1999]. So too, in this section we analyze the horizontal and vertical porosity geostatistics of the cobbleand-sand aquifer as a whole at the BHRS.

\subsubsection{Level 1 Horizontal Experimental and Model Variograms}

[24] The level 1 horizontal experimental variogram with $2 \sigma$ JKCI might be interpreted visually as having either scatter around a sill at $\sim 0.0039$ or as having periodic structure (Figure 6a). Close examination of the short-range region of this variogram suggests that the decrease in variogram magnitude at $\sim 5 \mathrm{~m}$ lag may be a "hole," or an indication of repetition distance for short-range periodic structure [e.g., Prosser et al., 1995; Jensen et al., 1996] rather than random scatter in a monotonically increasing rising limb of a transition-type structure. Indeed, the best fit to the omnidirectional horizontal variogram based on both visual and least squares criteria is a nested periodic model:

$$
\gamma(h)=c_{0}+c_{1}\left[1-\sin \left(h / a_{1}\right)\right]+c_{2}\left[1-\sin \left(h / a_{2}\right)\right]
$$

where $c_{0}$ is the nugget; $c_{1}$ and $c_{2}$ are sills for nested structures 1 and 2; and $a_{1}$ and $a_{2}$ are characteristic lengths for structures 1 and 2 . In a periodic structure, the characteristic length for a hole is $5 \pi a / 2$ which gives a length of $4.6 \mathrm{~m}$ for a hole in structure 1 and a length of $\sim 46 \mathrm{~m}$ for structure 2 (Table 2). Direct geologic explanation for periodic geostatistical structure is not available due to the difficulty of interpreting sedimentary facies associations from core in these coarse subsurface deposits, but we revisit this subject in section 6.3.1. Also, we note that exploratory review of directional horizontal experimental variograms was inconclusive.

\subsubsection{Level 1 Vertical Experimental and Model}

Variograms

[25] Unlike the horizontal variogram, the vertical experimental variogram of porosity values (Figure 6b) is best

\begin{tabular}{|c|c|c|c|c|}
\hline \multicolumn{5}{|c|}{ Kolomogorov-Smirnov Test for Equality of Two Distributions ${ }^{a}$} \\
\hline Units & $Z$ & $p$ Value & \multicolumn{2}{|c|}{ Conclusion } \\
\hline 4 and 3 & 12.409 & $<0.001$ & \multicolumn{2}{|c|}{ Different distributions } \\
\hline 3 and 2 & 16.905 & $<0.001$ & \multicolumn{2}{|c|}{ Different distributions } \\
\hline 2 and 1 & 13.323 & $<0.001$ & \multicolumn{2}{|c|}{ Different distributions } \\
\hline 4 and 2 & 3.826 & $<0.001$ & \multicolumn{2}{|c|}{ Different distributions } \\
\hline 3 and 1 & 3.397 & $<0.001$ & \multicolumn{2}{|c|}{ Different distributions } \\
\hline \multicolumn{5}{|c|}{ Levene's Test for Equality of Variances ${ }^{\mathrm{a}}$} \\
\hline Units & $F$ & $p$ Value & \multicolumn{2}{|c|}{ Conclusion } \\
\hline 4 and 3 & 210.809 & $<0.001$ & \multicolumn{2}{|c|}{ Different variances } \\
\hline 3 and 2 & 92.307 & $<0.001$ & \multicolumn{2}{|c|}{ Different variances } \\
\hline 2 and 1 & 84.478 & $<0.001$ & \multicolumn{2}{|c|}{ Different variances } \\
\hline 4 and 2 & 43.364 & $<0.001$ & \multicolumn{2}{|c|}{ Different variances } \\
\hline 3 and 1 & 3.004 & 0.083 & \multicolumn{2}{|c|}{ Null hypothesis not rejected } \\
\hline \multicolumn{5}{|c|}{$t$ Test for Equality of Means ${ }^{\mathrm{a}}$} \\
\hline Units & $t$ & d.f. & $p$ Value & Conclusion \\
\hline 3 and 1 & 6.359 & 1252 & $<0.001$ & $\begin{array}{l}\text { Different } \\
\text { means }\end{array}$ \\
\hline
\end{tabular}

Table 1. Population Comparisons With Kolomogorov-Smirnov Test and With $F$ and $t$ Tests

${ }^{\mathrm{a}}$ Descriptive statistics for units are given in Figure 5. 

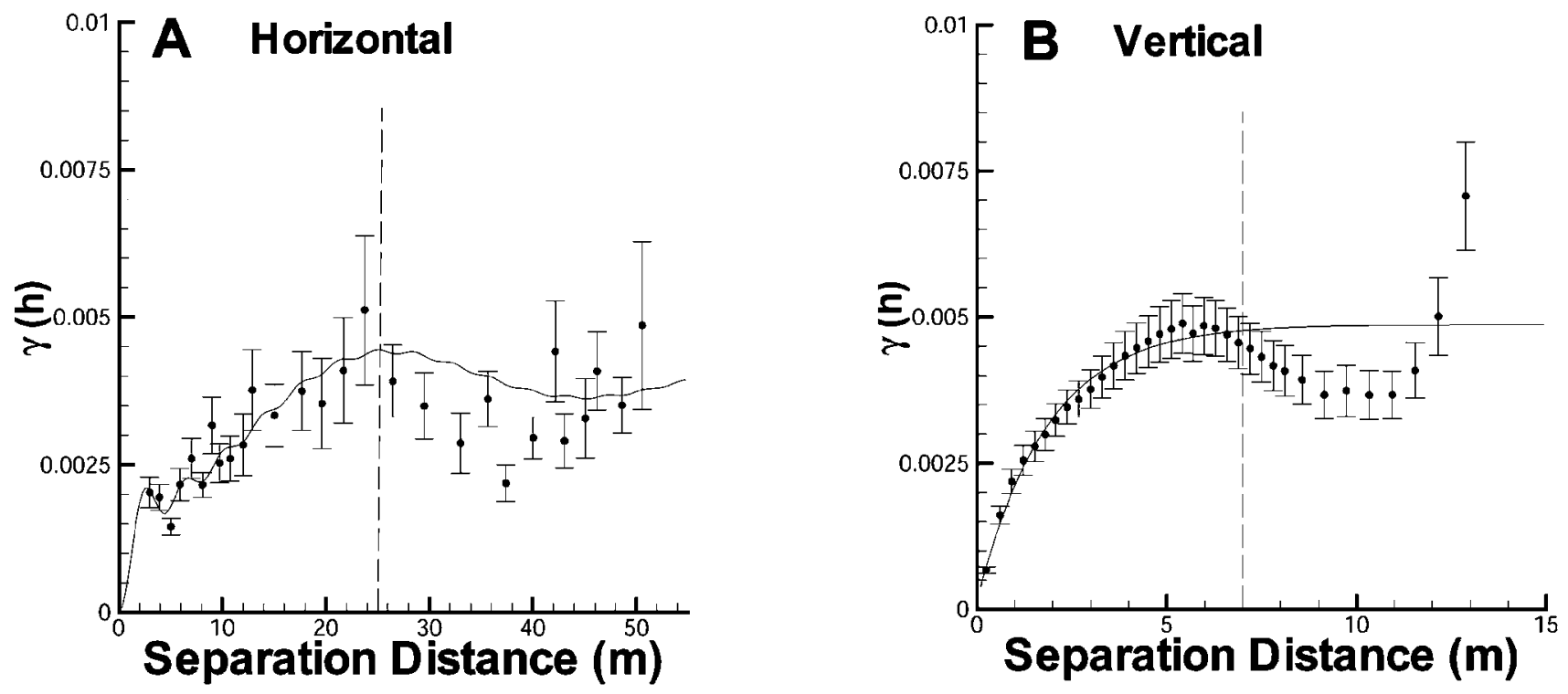

Figure 6. (A) Horizontal experimental variogram for the fluvial aquifer as a whole (level 1) at the BHRS. Variogram fit with nested periodic model. (B) Level 1 vertical experimental variogram fit with exponential model. Data used for fits only to one half maximum separation distance (vertical dashed lines in (A) and (B)).

fit, in the least squares sense, by an exponential model (Table 2). In addition to this difference in horizontal and vertical model structures at hierarchical level 1 [see also Journel and Huijbregts, 1978, Figure III.9, p. 170], the model sill value of 0.0048 for the vertical variogram is significantly higher than the value of 0.0039 for the horizontal variogram (Table 2 and Figure 6). This difference in horizontal and vertical sill values exceeds the uncertainty in the data.

\subsubsection{Nonstationarity at Hierarchical Level 1}

[26] Although geostatistical structure models can be fit to the horizontal and vertical porosity variograms at the BHRS, such structure models may not be useful for subsequent stochastic modeling if the system on which the structure models are based is nonstationary. Nonstationarity can be tested under the intrinsic hypothesis by examining whether the means of porosity values and the variances of differences between porosity values as a function of lag are

Table 2. Geostatistical Model Parameters for Hierarchical Levels 1, 2, and 3 at the BHRS

\begin{tabular}{|c|c|c|c|c|c|c|}
\hline & Model & Nugget $\left(c_{o}\right)$ & $\begin{array}{l}\text { Characteristic } \\
\text { Length }(a), \mathrm{m}\end{array}$ & Range, $\mathrm{m}$ & Structure Sill $\left(c_{i}\right)$ & $\left(\begin{array}{c}\text { Full Sill } \\
c=\sum_{i=1}^{n} c_{i}\end{array}\right.$ \\
\hline \multicolumn{7}{|c|}{ Vertical } \\
\hline \multicolumn{7}{|l|}{ Level 1} \\
\hline Structure & exponential & - & 1.71 & 5.13 & 0.00481 & 0.00481 \\
\hline \multicolumn{7}{|l|}{ Level 2} \\
\hline Unit 1 & exponential & $1.44 \times 10^{-4}$ & 0.455 & 1.37 & 0.00032 & 0.000469 \\
\hline Unit 2 & exponential & 0 & 0.422 & 1.27 & 0.00143 & 0.00143 \\
\hline Unit 3 & exponential & $7.98 \times 10^{-5}$ & 0.314 & 0.94 & 0.00035 & 0.00043 \\
\hline Unit 4 & periodic & $3.51 \times 10^{-4}$ & $0.230^{\mathrm{a}}$ & $1.81^{\mathrm{a}}$ & $0.00188^{\mathrm{a}}$ & $0.00223^{\mathrm{a}}$ \\
\hline Unit 5 & - & - & - & - & - & - \\
\hline \multicolumn{7}{|l|}{ Level 3} \\
\hline Subunit A & periodic & $1.88 \times 10^{-4}$ & $0.124^{\mathrm{a}}$ & $0.97^{\mathrm{a}}$ & 0.00019 & 0.00038 \\
\hline Subunit B & periodic & $2.62 \times 10^{-4}$ & $0.134^{\mathrm{a}}$ & $1.05^{\mathrm{a}}$ & 0.00026 & 0.00052 \\
\hline Subunit C & - & - & - & - & - & - \\
\hline \multicolumn{7}{|c|}{ Horizontal } \\
\hline \multicolumn{7}{|l|}{ Level 1} \\
\hline Structure 1 & periodic & - & $0.588^{\mathrm{a}}$ & $4.6^{\mathrm{a}}$ & $0.00167^{\mathrm{a}}$ & - \\
\hline Structure 2 & periodic & - & $5.825^{\mathrm{a}}$ & $46^{\mathrm{a}}$ & $0.00226^{\mathrm{a}}$ & - \\
\hline Structures 1 and 2 & nested periodic & - & - & - & - & $0.0039^{\mathrm{a}}$ \\
\hline \multicolumn{7}{|c|}{ Level 2} \\
\hline Unit 1 & nugget & 0.00054 & - & - & - & 0.00054 \\
\hline Unit 2 & nugget & 0.00137 & - & - & - & 0.00137 \\
\hline Unit 3 & nugget & 0.00054 & - & - & - & 0.00054 \\
\hline Unit 4 & nugget & 0.00196 & - & - & - & 0.00196 \\
\hline Unit 5 & - & - & - & - & - & - \\
\hline
\end{tabular}

${ }^{a}$ Parameters from periodic models (see equation (4)). 
constant in different regions of the investigated volume (equation (3)). To perform these tests we examine the statistics and geostatistics of the next smaller scale: hierarchical level 2, or the scale of $\sim 2$ to 9-m-thick subhorizontal sedimentary units separated by bounding surfaces.

\subsection{Porosity Statistics and Geostatistics of Hierarchical Level 2}

[27] The following analysis uses porosity data only from the 13 central area wells (inset in Figure 1) where data density is greatest and unit identification is best constrained. The pdf for Unit 5 (sand channel) has relatively few total measurements; the pdfs for the remaining four (cobble-dominated) units more closely approximate normal distributions (Figure 5). Experimental vertical and horizontal variograms for these five level 2 units are shown in Figures 7 and 8 , respectively. Although the sand unit is the easiest to identify and trace from core, well logs, and radar data, the experimental variograms for Unit 5 are erratic and exhibit the highest variance overall, likely due to the greater range of values and relatively few data points available. At this point, we cannot determine a geostatistical structure for Unit 5, the channel sand, and further analysis of this unit is not given here.

\subsubsection{Experimental and Model Variograms in Cobble-Dominated Units 1 and 3}

[28] Experimental vertical and horizontal variograms for Units 1 and 3 are similar in shape and in sill values, respectively (Figures 7 and 8 and Table 2). For the vertical experimental variograms of Units 1 and 3: sills and ranges are similar, and magnitudes of residuals are similar for fits to exponential, Gaussian, or spherical models. Fits to an exponential model, $\gamma(h)=c_{0}+c_{1}\left(1-e^{-h / a}\right)$, are shown in Figure 7; values for $c_{0}$ (nugget), $c_{1}$ (sill), and a (characteristic length) are given in Table 2 . Vertical ranges are $\sim 1$ to $1.4 \mathrm{~m}$.

[29] The horizontal variograms for Units 1 and 3 are best modeled with a pure nugget effect which might indicate that the horizontal ranges for these units are $\leq 2.5 \mathrm{~m}$, the smallest lag at the BHRS. However, the data from 13 wells may be insufficient to distinguish the horizontal structure [e.g., Journel and Huijbregts, 1978, p. 230]. For comparison we note that Jussel et al. [1994] reported $2.8 \mathrm{~m}$ horizontal characteristic lengths $(\sim 8.4 \mathrm{~m}$ ranges) for permeability from measurements in cobble-dominated units in similar deposits in Switzerland.

\subsubsection{Experimental and Model Variograms in Cobble-Dominated Units 2 and 4}

[30] Experimental vertical and horizontal variograms for Units 2 and 4 are not similar in shape or sill values (Figures 7 and 8 and Table 2). As with Units 1 and 3, the horizontal variograms for Units 2 and 4 exhibit a pure nugget effect. Fits of three transition-type models to the vertical experimental variogram for Unit 2 are similar (exponential model is shown in Figure 7c). Also, the sills of the horizontal and vertical variograms are similar for Unit 2. For Unit 4 the vertical variogram is best fit with a periodic model and the sills for vertical and horizontal variograms for Unit 4 are not similar (Figures $7 \mathrm{~d}$ and $8 \mathrm{~d}$ and Table 2). Close review of porosity-log character for Unit 4 reveals the presence of more-distinct zones of higher and lower porosity in Unit 4 than in other level 2 units (e.g., Figures $4 a$ and 4b). The presence of relatively distinct zones with different means and variances of porosity differences indicates that Unit 4 geostatistics are not stationary under the intrinsic hypothesis.

5.3.3. Level 2 Statistics and Geostatistics and Level 1 Nonstationarity

[31] Different stable sills (i.e., spatially uncorrelated variances) for vertical variograms of adjacent level 2 units are clear evidence that the random function, $Z(x)$, is not stationary in the investigated region of the BHRS at hierarchical level 1 (Table 2). This evidence of nonconstant spatial distribution also is supported with statistically significant differences in the geostatistical models of adjacent level 2 units based on Hotelling's $T^{2}$ test (Table 3) [see also Woodbury and Sudicky, 1991]. We included a nugget term in all geostatistical models in order to conduct the Hotelling's $T^{2}$ test.

\subsection{Porosity Statistics and Geostatistics of Level 3 Subunits in Unit 4}

[32] Coarse fluvial deposits exhibit abrupt as well as gradational lateral and vertical changes associated with complex depositional and erosional processes at several scales [e.g., Bluck, 1979; Smith, 1985]. Figure 3 shows such variability in facies and scale at a nearby road cut in deposits believed to be similar to those in the subsurface at the BHRS. With this scale of variability in mind, Unit 4 was subdivided into low, intermediate, and high porosity subunits (subunits A, B, and C, respectively). Unlike the level 2 units which are continuous layers in the central area of the BHRS, subunits $\mathrm{A}, \mathrm{B}$, and $\mathrm{C}$ are discontinuous lenses and patches. Distributions of porosity values of these subunits approximate normal populations (Figure 9). Only vertical experimental variograms have been evaluated for possible model structures. Vertical variograms for subunits A and B are best fit with periodic structures (Figure 10 and Table 2). For subunit $\mathrm{C}$ (high porosity subunit) the vertical variogram exhibits high variance at short lags (Figure 10c) and any model structure fit would be speculative.

\section{Variograms in Hierarchical Systems}

[33] In this section, we use the geometry, statistics, and geostatistics of hierarchical levels 1 and 2 to examine both the cause of inconsistent sills in different directions (section 6.1), and the composition of variograms of layered systems, some of which also exhibit periodic variograms (section 6.2). Then we extend the analysis to show, quantitatively, how the variogram of point measurements from a layered system with multiple facies is an aggregate of both withinlayer and between-layer variograms as a function of lag. In

Figure 7. (opposite) Vertical variograms and fitted models for hierarchical level 2 units in the central area of the BHRS. Data used for fits only to one half maximum separation distance (vertical dashed lines in (A) to (D)). Note significant increase in scale for the variogram function ( $y$ axis) for Units 4 and 5 (D and E). (A) Unit 1, fit with an exponential model. (B) Unit 3, fit with an exponential model. (C) Unit 2, fit with an exponential model. (D) Unit 4, fit with a periodic model. (E) Unit 5, not fit with a model. 

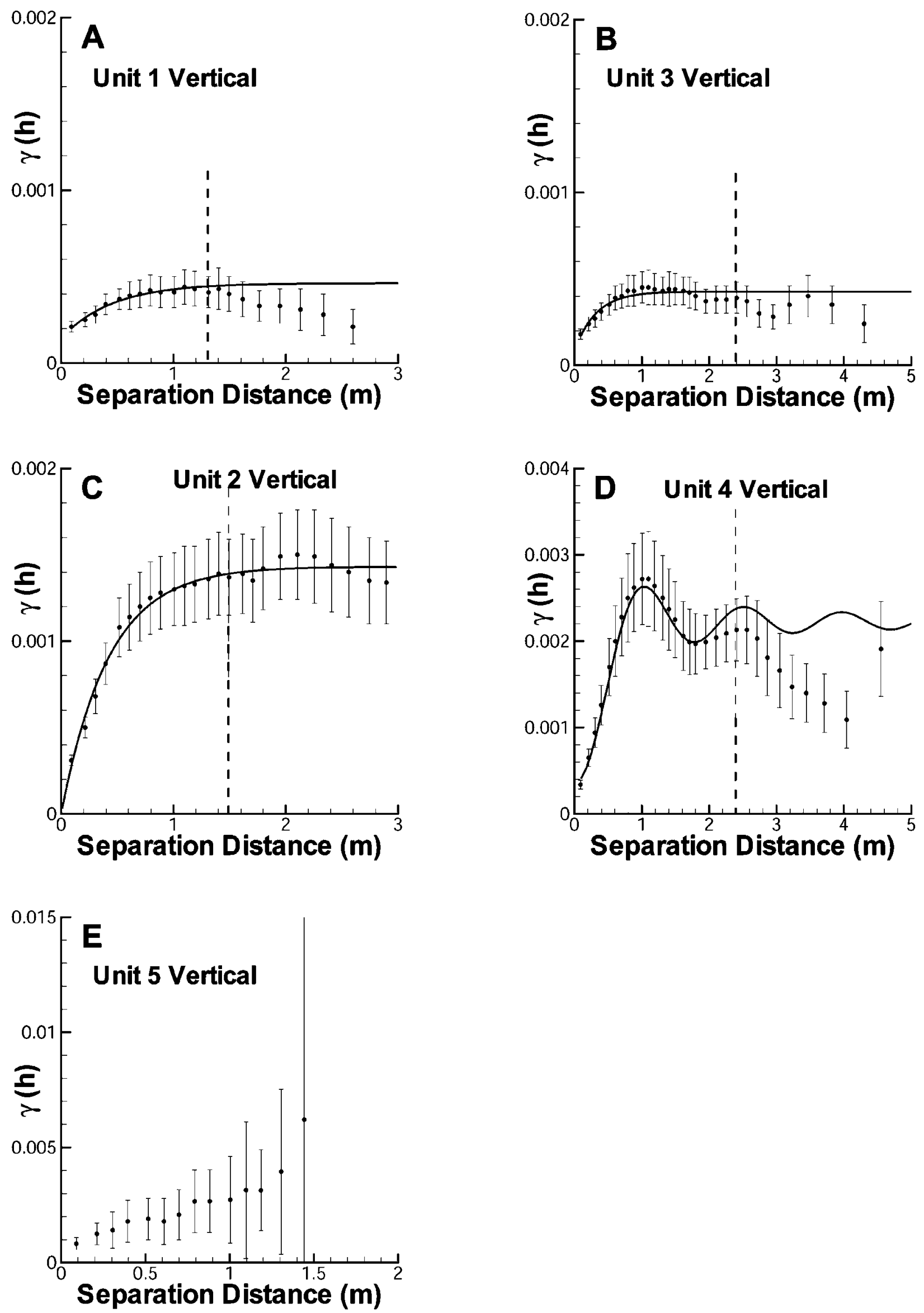

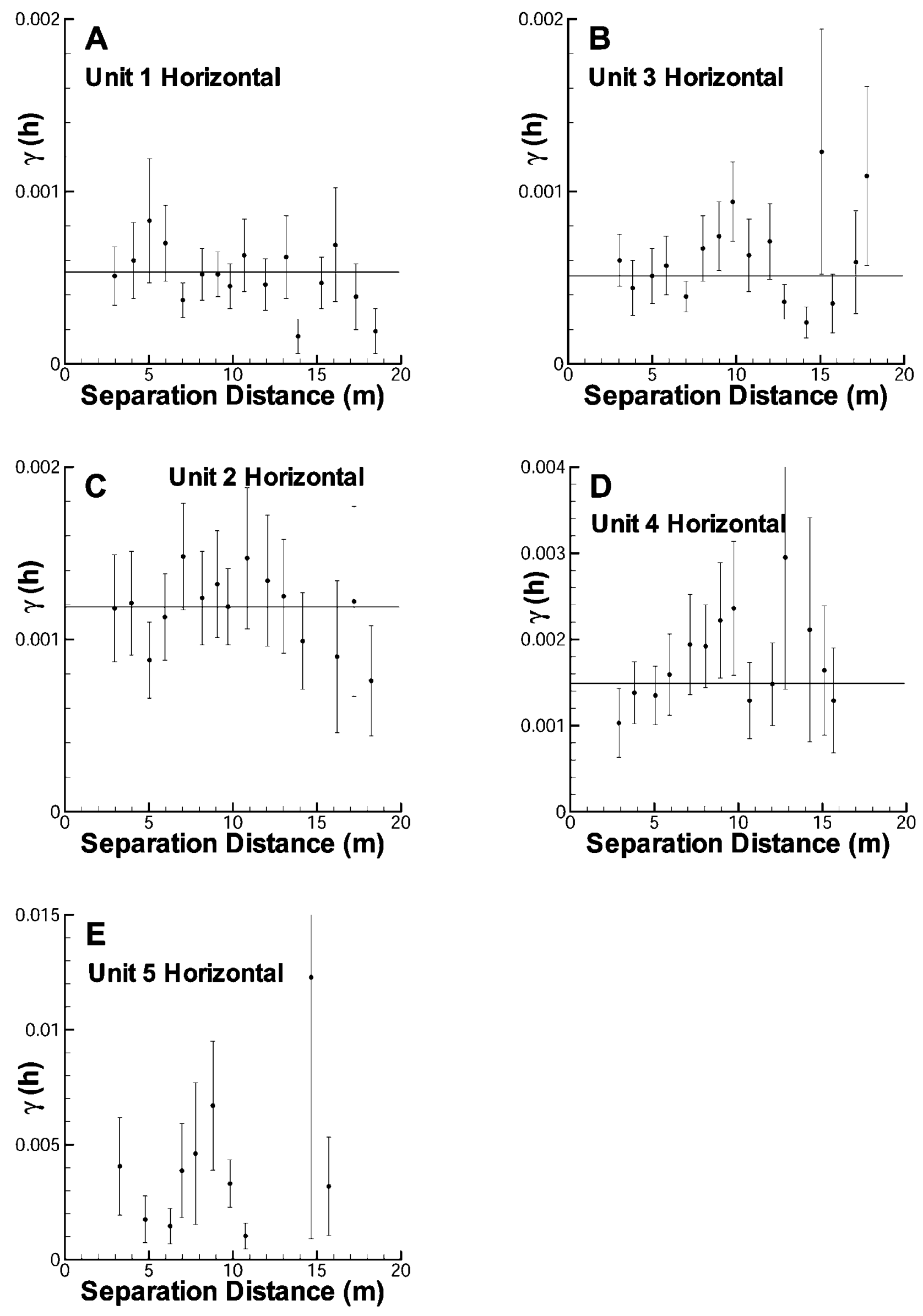
Table 3. Hotelling's $T^{2}$ Test Results Comparing Parameters of Exponential Geostatistical Models of Porosity for Level 2 CobbleDominated Units 1, 2, and 3

\begin{tabular}{lcc}
\hline Units & $\begin{array}{c}F_{p, n-p}{ }^{\text {a }}{ }^{2} \text { Relation to } \\
\text { Criterion at } 0.01 \text { Probability }\end{array}$ & Conclusion \\
\hline 1 and 2 & $8800>7.59$ & Different structures \\
2 and 3 & $9200>4.5$ & Different structures \\
1 and 3 & $14>4.5$ & Different structures \\
\hline${ }^{\text {a } F_{p, n-p} \text { is calculated as } \frac{n-p}{(n-1) p} T^{2} \text { where } T^{2} \text { is Hotelling's } T^{2} \text { statistic, } n \text { is }}$ \\
the number of experimental semivariogram data points that are fit, and $p=3$ \\
or the number of parameters in the semivariogram model.
\end{tabular}

section 6.3 we generalize this finding to any system at a given hierarchical level with stationary units at one or more smaller-scale hierarchical levels, and we use this generalization to examine sources of horizontal periodic structure expressed at hierarchical level 1 .

\subsection{Inconsistent Vertical and Horizontal Sills in a Layered System}

[34] To investigate the cause for different sill values in the vertical and horizontal directions we consider a sedimentary aquifer: (1) with horizontal layers of several different types of deposits, or facies, that may recur in a random process and (2) with each facies having a different mean, variance, and sill, and having a stationary and normal distribution for the parameter of interest. We also assume that measurements have been taken at numerous vertical transects with uniform, dense spacing. Such a layered system is an idealization of the four cobble-dominated units in the central area of the BHRS (Figure 11). We consider this four-layer system to be comprised of three facies (Facies A, B, and C). That is, in the following analysis we treat layers 1 and 3 as a recurring facies (Facies A) based on the similarity of means, variances, and geostatistics for Units 1 and 3 (Figures 5 and 7 and Tables 1-3).

\subsubsection{Horizontal Geostatistics of a Four-Layer System With Three Facies}

[35] In the horizontal direction of the model four-layer system, data pairs will only include measurements within the population of a given layer (Figure 11). The global omnidirectional horizontal experimental variogram of a parameter for such a system is the weighted average of the variograms for each of the layers, with a given weight being the thickness fraction of the whole system for a given layer (i.e., arithmetic averaging of parallel subsystems). The global sill will be less than the greatest sill of any layer because of the averaging process of a parallel system:

$$
\operatorname{Sill}_{h}=\sum_{i=1}^{N} \omega_{i} \cdot c_{i}
$$

where $N$ is the number of layers; $i$ is an individual layer; $\omega_{i}$ is the weight or volume fraction for an individual layer; $c_{i}$ is the sill for an individual layer, and $h$ identifies the horizontal
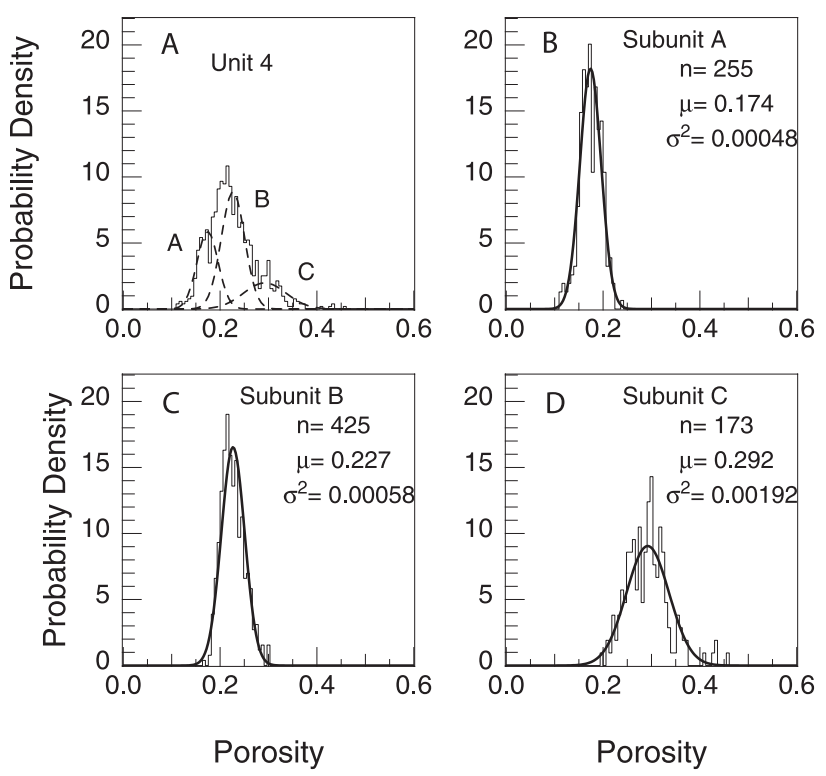

Figure 9. Pdfs for hierarchical level 3 subunits in Unit 4 in the central area of the BHRS. (A) Pdf for Unit 4 as a whole with normal distributions for the three subunits superimposed. (B) Pdf of subunit A; normal distribution superimposed. (C) Pdf of subunit B; normal distribution superimposed. (D) Pdf of subunit $\mathrm{C}$; normal distribution superimposed.

direction. Alternatively, this formulation could be used on a facies, rather than layer, basis.

\subsubsection{Vertical Geostatistics of a Four-Layer System With Three Facies}

[36] In the vertical direction we write the formulation for three facies rather than four layers. This is for illustrative purposes; the same net result occurs if it is written for four facies or layers with the same two layers having identical parameter distributions. Regardless, some data pairs will consist of measurements between different facies; others will consist of measurements within a given facies. Data pairs within a given type of facies will occur at both short lag spacings (up to the thickness of a given facies body) and longer lag spacings that coincide with intervals spanning intervening regions of different facies (e.g., Facies A in layers 1 and 3 in Figure 11). With few exceptions, lags will include a mix of pairs from similar and from different facies, and so the proportions of data pairs within facies and between facies change as lags change. The global vertical sill value includes weighted averages of both within-facies sill values and between-facies sills, and may be approximated by:

$$
\operatorname{Sill}_{v}(h) \cong \sum_{i j=1}^{(f+1) f / 2} \omega_{i j}(h) \cdot c_{i j}
$$

where $i j$ defines the facies contributing elements of a data pair such that $i=j$ for within-facies pairs and $i \neq j$ for

Figure 8. (opposite) Horizontal variograms and fitted models for hierarchical level 2 units in the central area of the BHRS. Note significant increase in scale for the variogram function ( $y$ axis) for Units 4 and 5 (D and E). (A) Unit 1, fit with a pure nugget model. (B) Unit 3, fit with a pure nugget model. (C) Unit 2, fit with a pure nugget model. (D) Unit 4, fit with a pure nugget model. (E) Unit 5 , not fit with a model. 

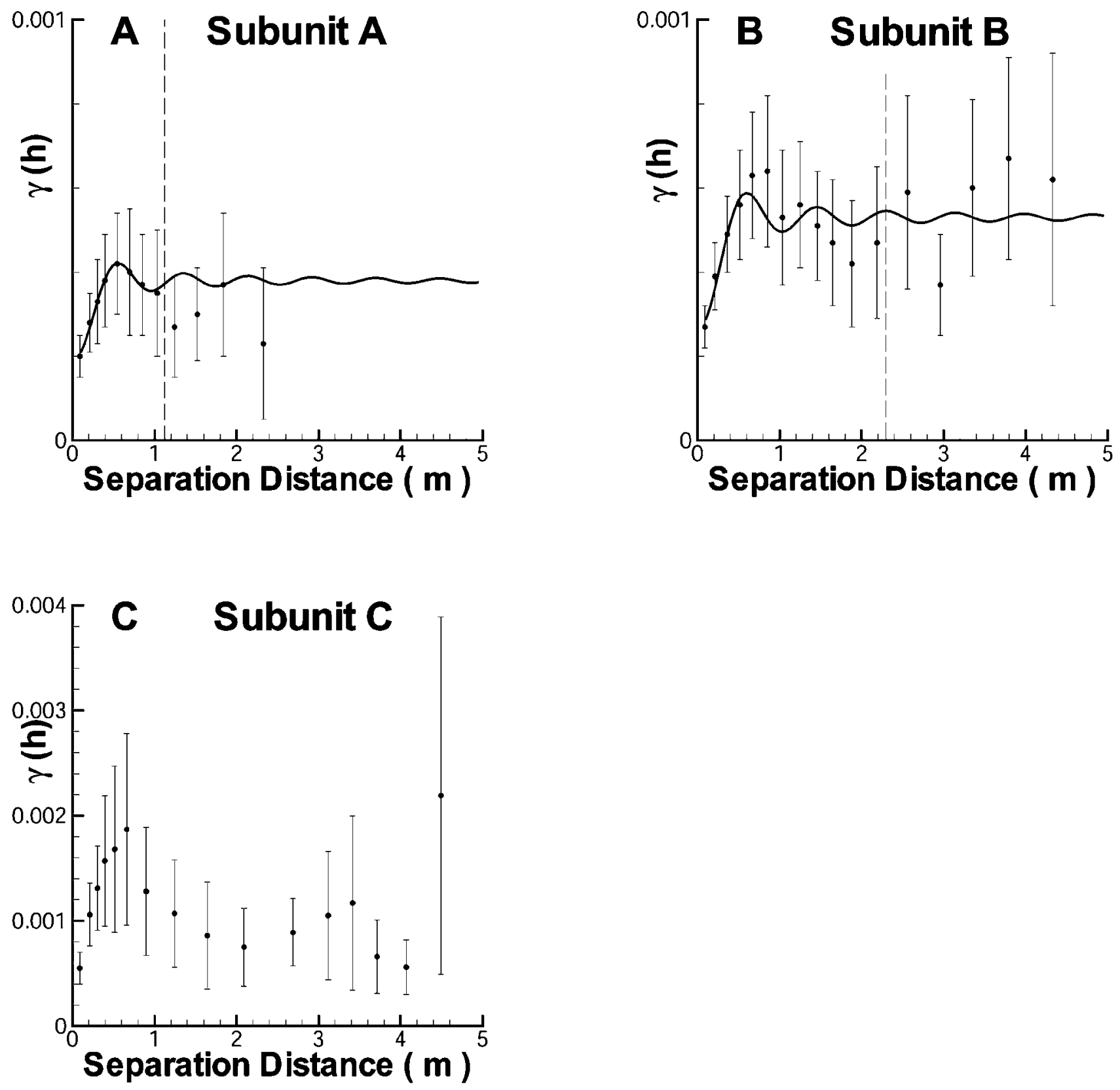

Figure 10. Vertical variograms for hierarchical level 3 subunits in Unit 4. Data used for fits only to one half maximum separation distance (vertical dashed lines in (A) and (B)). (A) Subunit A fit with periodic model with a nugget. (B) Subunit B fit with periodic model with a nugget. (C) Subunit C not fit with a model due to high short-range variance.

between-facies pairs, and $v$ identifies the vertical direction. In the four-layer three-facies system of Figure 11 there are $(f+1) f / 2$ or six unique facies combinations (where $F$ is the number of facies) including each of the three facies with itself. If measurements are uniformly spaced along transects in the vertical direction (as with well logs at the BHRS) then the number of data pairs for a given facies, or combination of different facies, is proportional to the volume fraction $\left(\omega_{i j}\right)$ of the given facies, or combination of different facies, that are contributing to the variogram estimator at that lag. Equation (6) is an approximation because it ignores the rising limb of those component variograms which have short-range correlation. The effect of this simplification is minor except at initial lags, and is removed altogether with more-general treatments given in the next sections.

[37] To calculate a given between-facies sill value, $c_{i j}$, for equation (6) we start by considering $c_{i j}$ as the cross-variogram between facies $i$ and $j$. Let $z_{k}(x)=\mu_{i}+e_{k}(x)$ where $\mu_{i}$ is the mean of the data in facies $i, k$ is the index counter for individual measurements in facies $i$, and $e_{k}(x)$ is the deviation of measurement $z_{k}$ from the mean. The variance of $z_{k}$ in facies $i$ is $\sigma_{i}^{2}=\frac{1}{N_{i}} \sum_{k=1}^{N_{i}} e_{k}^{2}$ where $N_{i}$ is the number of measurements in facies $i$. Similarly, for facies $j, z_{l}(x)=\mu_{j}+e_{l}(x)$. It is reasonable to assume that $e_{k}(x)$ in facies $i$ and $e_{l}(x+h)$ in 


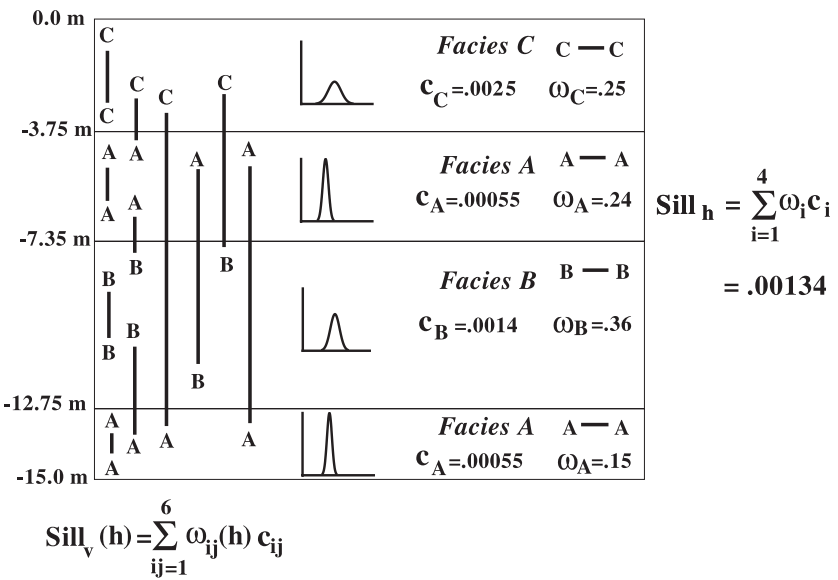

Figure 11. Schematic diagram of a model system similar to the BHRS having four-layers with three facies. Pdfs for parameter of interest are given in each layer; two layers have the same pdf and are the same facies (Facies A). Sill values for each facies $\left(c_{A}\right.$ to $\left.c_{C}\right)$ reflect the variances of the pdfs for corresponding facies. For the horizontal direction, measured values are paired only with values from the same layer (shown schematically by bold horizontal lines linking facies letter identifiers). The global horizontal sill is calculated from layer properties as the sum of individual layer sills weighted by thickness proportion (equation (5)). For the vertical direction, measured values are paired with same-facies and with different-facies values (shown schematically by bold vertical lines linking facies letter identifiers) in proportions that vary by lag. The global vertical "sill" is calculated from lag-weighted individualand combined-facies values (equation (6)).

facies $j$ are uncorrelated because facies $i$ and $j$ are separate populations. The cross-variogram, then is:

$$
\begin{gathered}
2 c_{i j}=\frac{1}{N_{i}} \sum_{k=1}^{N_{i}} \frac{1}{N_{j}} \sum_{l=1}^{N_{j}}\left(z_{k}-z_{l}\right)^{2} \\
2 c_{i j}=\frac{1}{N_{i}} \sum_{k=1}^{N_{i}} \frac{1}{N_{j}} \sum_{l=1}^{N_{j}}\left[\left(\mu_{i}-\mu_{j}\right)+e_{k}-e_{l}\right]^{2}
\end{gathered}
$$

For a large number of measurements, the sum of cross terms of the square is approximately zero since $e_{k}$ is zero mean and independent of $\left(\mu_{i}-\mu_{j}\right)$ and $e_{l}$, so:

$$
\begin{gathered}
2 c_{i j}=\frac{1}{N_{i}} \sum_{k=1}^{N_{i}} \frac{1}{N_{j}} \sum_{l=1}^{N_{j}}\left[\left(\mu_{i}-\mu_{j}\right)^{2}+e_{k}^{2}+e_{l}^{2}\right] \\
2 c_{i j}=\left(\mu_{i}-\mu_{j}\right)^{2}+\frac{1}{N_{i}} \sum_{k=1}^{N_{i}} e_{k}^{2}+\frac{1}{N_{j}} \sum_{j=1}^{N_{j}} e_{l}^{2} \\
c_{i j}=\frac{\left(\mu_{i}-\mu_{j}\right)^{2}+\sigma_{i}^{2}+\sigma_{j}^{2}}{2}
\end{gathered}
$$

[38] From equation (7e) it can be seen that a given combined-facies sill will be constant and will be higher than both source population variances except where the two source populations have very similar means but different variances (e.g., Units 2 and 4, see Figure 5 and Table 1). Therefore, the global vertical variogram commonly will have a larger sill value than the global horizontal sill in a layered multifacies system [see also Kupfersberger and Deutsch, 1999]. Although the existence of combined-facies terms explains higher vertical than horizontal sill values in layered systems, determining a value for the vertical sill is more complicated than for the horizontal direction because the proportions of combinedfacies pairs, or weights, for each contributing geostatistical structure are not uniform but rather are a function of lag (equation (6)).

\subsection{Vertical Variogram of a Layered Multifacies System}

[39] A variogram of a multifacies system may be decomposed quantitatively to show the relative contributions of geostatistical structures of individual and combined facies as a function of lag. Rubin [1995, equation (9), p. 2463] developed an expression for the covariance of a bimodal permeability field created by the presence of two facies where indicator random functions represent the occurrence
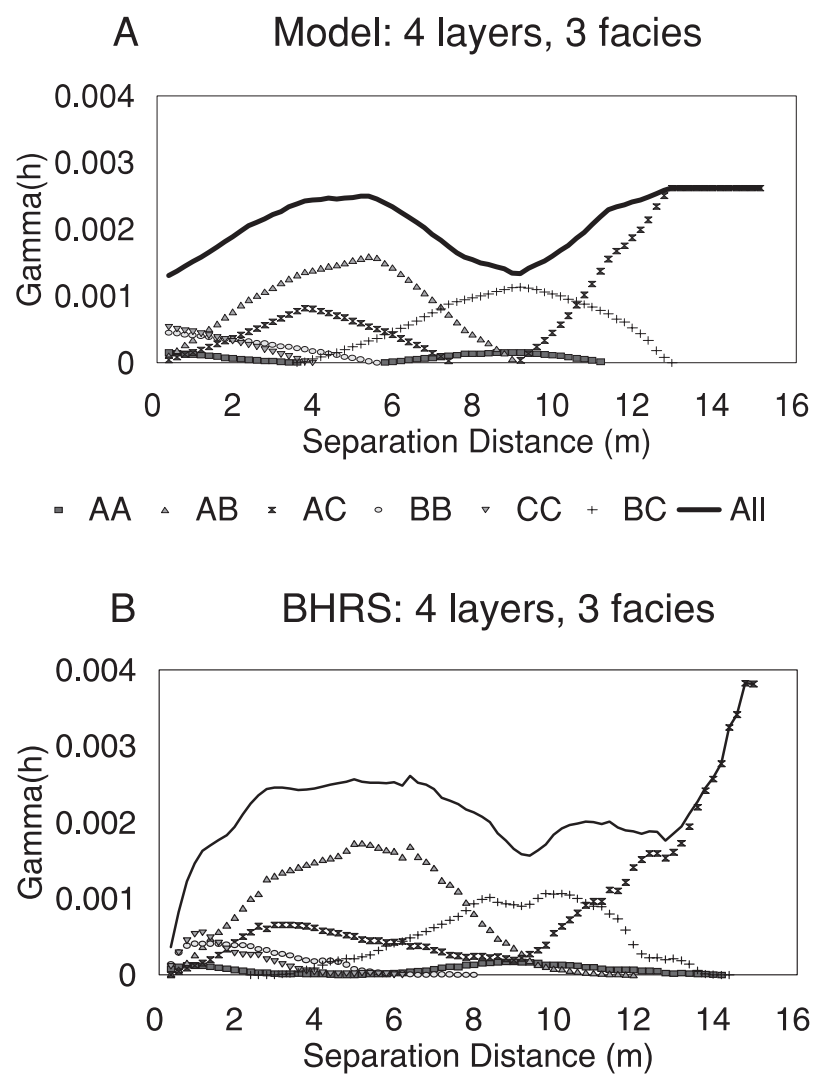

- $A A \triangle A B=A C \cdot B B \cdot C C+B C-A l l$

Figure 12. Global or level 1 (solid line) and component (symbols) vertical variograms weighted by volume fraction per lag for a four-layer, three-facies system using equation (9). (A) Variograms from model of Figure 11. Note shortrange structure is not included in model variograms. (B) BHRS experimental variograms. 
of the facies and continuous random functions represent the permeability within each facies. Rubin's equation is written in terms of the covariance function as:

$$
\begin{aligned}
C(h)= & {\left[C_{I}(h)+\omega_{1}^{2}\right] C_{1}(h)+\left[C_{I}(h)+\omega_{2}^{2}\right] C_{2}(h) } \\
& +\left(\mu_{1}-\mu_{2}\right)^{2} C_{I}(h)
\end{aligned}
$$

where $C$ is the covariance function, $C(h)=\sigma^{2}-\gamma(h)$, subscripts 1 and 2 refer to the two facies; subscript I is the indicator for the occurrence of either facies; and other parameters are as defined previously. In this formulation, the weighting of the contribution by a given facies to the global variogram is divided into: (1) the overall volume fraction of a given facies $\left(\omega_{1}=1-\omega_{2}\right)$ which is constant for all lags; and (2) a lag-variable contribution defined by the geostatistical structure, $C_{I}(h)$, of the stationary distribution of facies for combined-facies contributions. This bimodal stationary system can be expanded to any number of facies having pair-wise stationary structures.

[40] The level 2 units at the BHRS, however, do not occur in stationary paired-indicator structures. This may be seen by inspection of Figure 11: Different vertical segments of this relatively thin system with few layers have different indicator variograms because of changes in the relative proportions of layers. In such a nonstationary hierarchical system, the lag-variable contributions to the global variogram by the combined-facies structures are not predictable by a stationary geostatistical structure $C_{I}(h)$. Therefore, the weighting of combined-facies structures reduces to each fraction of total data pairs for a given lag, as for the individual facies. The vertical variogram for such a nonstationary system (Figure 11) is:

$$
\gamma_{v}(h)=\sum_{i j=1}^{(f+1) f / 2} \omega_{i j}(h) \cdot c_{i j} \cdot \gamma_{v i j}^{*}(h)
$$

where $\gamma^{*}$ is the normalized variogram, or the geostatistical structure divided by the sill. Figure 12 shows the decomposition of the vertical variogram for the nonstationary, three-facies, four-layer system of Figure 11, and for the similar real system of four cobble-dominated layers at the BHRS.

[41] The global vertical variogram and component vertical variograms of the real system are more irregular than the model system because the units are not perfectly horizontal layers (Figure 4). Also, for simplicity, the component variograms of the modeled system do not include short-range correlation so initial magnitudes will be slightly smaller than shown in Figure 12a for each component variogram in the model. However, variograms for adjacent combined facies in the real system have short-range correlation because porosity variation at some unit contacts at the BHRS is gradual (Figure 4). And it is evident (Figure 12) that component weighted variogram contributions to the global variogram change with lag.

\subsection{Multifacies Structures and Hierarchical Systems}

[42] Many natural systems have multiple facies that occur in nonlayered patchy distributions as lenses, elongate channels, and other combinations of body geometries. Consider a common type of fluvial system which, at hierarchical level 2 , has numerous lenses or channels adjacent to each other as

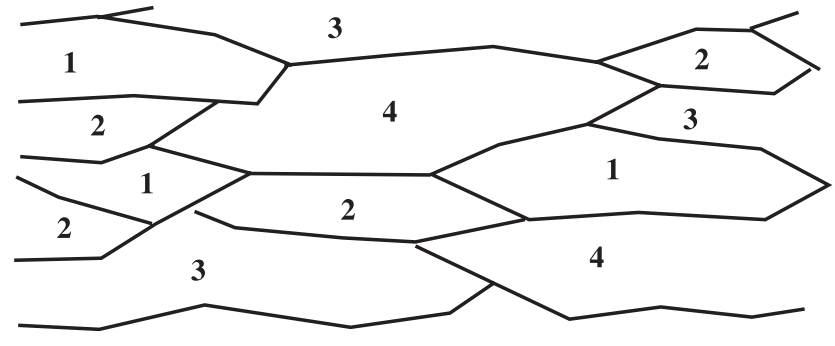

$$
\text { Number of facies }=f=4
$$

$$
\text { Number of unique pairs }=(f+1) f / 2=10
$$

$$
\gamma_{x_{a}}(h)=\sum_{i j=1}^{(f+1) f / 2} \omega_{x_{a} i j}(h) \cdot c_{i j} \cdot \gamma_{x_{a} i j}^{*}(h)
$$

Figure 13. Example of general multifacies system with four level 2 facies in a patchy distribution. Global geostatistical structure includes data pairs with measurements from individual facies and data pairs with measurements from different facies. Equation (10) is valid in any direction, and in nonstationary or stationary level 1 systems. Notation given in text.

in alluvial fans [e.g., Carle et al., 1998], or has lenses both adjacent to each other (e.g., Figure 3) and isolated in a dominant matrix facies as in some cobble-and-sand deposits [e.g., Jussel et al., 1994]. In nonlayered systems of multifacies structures (shown schematically in Figure 13) the different facies bodies (1) are paired in all directions, not just vertically across horizontal layer boundaries and (2) occur in different sequences along different transects in all directions. That is, relative proportions or weights may change as a function of lag in any direction.

[43] Commonly a given deposit will consist of a limited number of recurring facies types which have stationary within-facies geostatistics. The variogram for such a general system of multifacies structures is a logical extension of equation (9):

$$
\gamma_{x_{a}}(h)=\sum_{i j=1}^{\frac{(f+1) f}{2}} \omega_{x_{a} i j}(h) \cdot c_{i j} \cdot \gamma_{x_{a} i j}^{*}(h)
$$

where $x_{a}$ is any given direction. Equation (10) is valid for multifacies systems at one or several hierarchical levels as long as each individual facies or subfacies body in the deposit is continuous within bounding surfaces (Figure 13). An experimental variogram for a multifacies system can be expressed in this form if the source facies for data points can be identified, regardless of whether the overall sampling distribution and numbers of data pairs (and hence, weights) represent true proportions of individual-facies and mixedfacies structures.

\subsubsection{Decomposition Analysis of Level 2 and Level 3} Multifacies Structures at the BHRS

[44] Variogram decomposition provides the opportunity to determine (1) what individual- and/or combined-facies structures are significant contributors to experimental variogram features (e.g., short-range periodicity) and (2) whether 

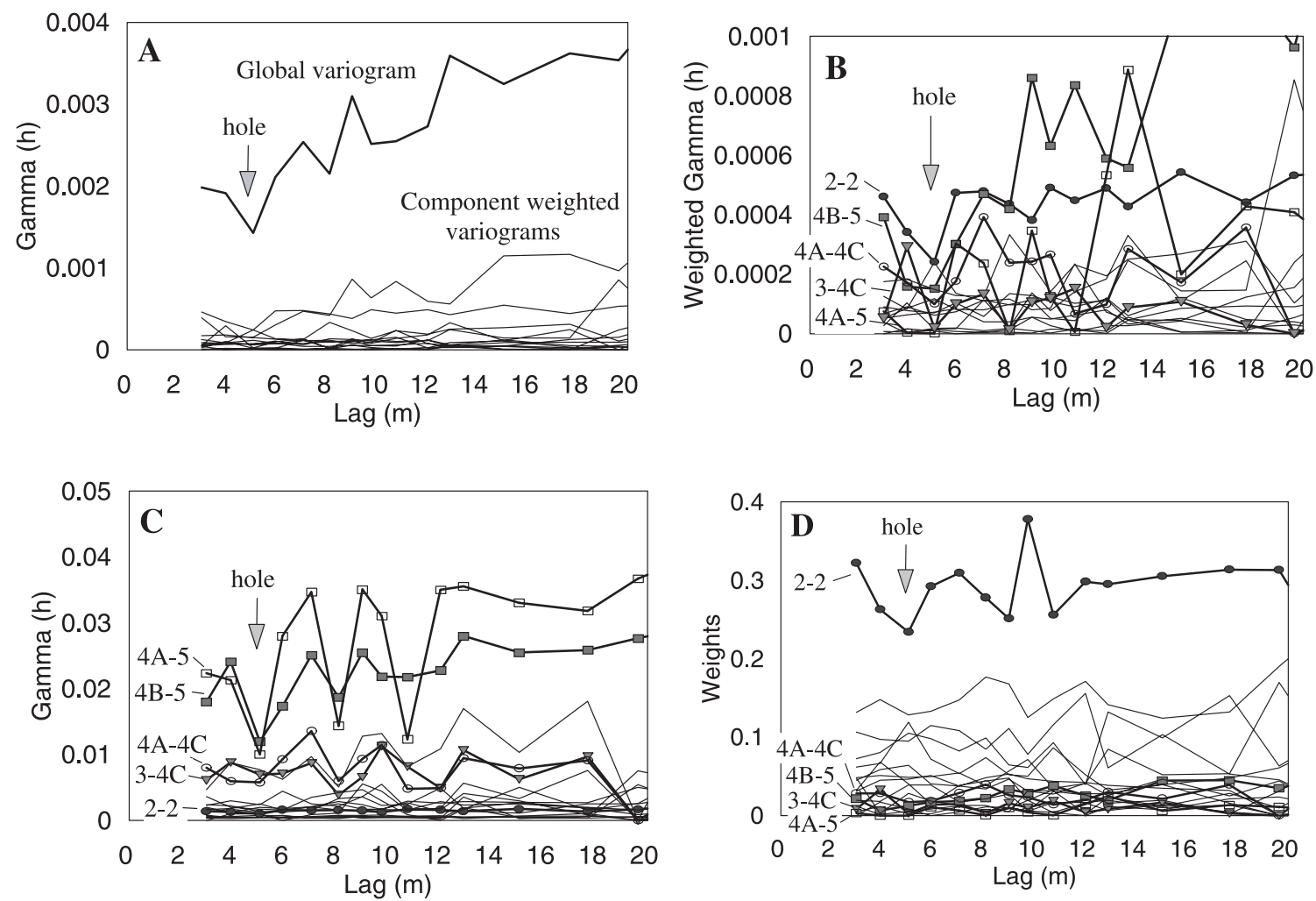

Figure 14. (A) Global horizontal variogram (bold line, compare with Figure 6a) and component weighted variograms (thin lines, undifferentiated) for individual and combined level 2 facies and level 3 subfacies. (B) Component weighted variograms of (A) showing that the hole at $\sim 5 \mathrm{~m}$ lag is due to reductions in five component weighted variograms: (1) Unit 2 (2-2); (2) Subunit B of Unit 4 combined with Unit 5 (4B-5); (3) Subunit A of Unit 4 combined with subunit C of Unit 4 (4A-4C); (4) Unit 3 combined with subunit C of Unit 4 (3-4C); and (5) Subunit A of Unit 4 combined with Unit 5 (4A-5). (C) Component (unweighted) variograms of (A) showing that the hole at $\sim 5 \mathrm{~m}$ lag is apparent in only two $(4 \mathrm{~A}-5$ and $4 \mathrm{~B}-5)$ of the five component variograms that are responsible for the hole. Note also that the hole at $\sim 8 \mathrm{~m}$ lag in the global variogram (A) is apparent in all four combined-facies variograms. (D) Plot of weights by lag for each component variogram shows: (1) contribution to hole at $\sim 5 \mathrm{~m}$ lag by Unit 2 is due to relatively reduced numbers of data pairs (rather than variogram magnitude - see (C)); and (2) relatively minor downward flexes for weights of $3-4 \mathrm{C}$ and $4 \mathrm{~A}-4 \mathrm{C}$ complement moderate downward flexes for variograms of these combined-facies variograms $(\mathrm{C})$.

the contribution by a given individual- or combined-facies structure is due to relative magnitude of the component variogram, to weighting of the component variogram, or to both. It is important to note that, although the component weights or variograms may not be fully accurate representations of true proportions of structures for a deposit or realization due to incomplete or disproportionate sampling, they are exact as components of the global experimental variogram based on available data and data treatment (e.g., lag intervals, angular tolerances).

[45] Using equation (10) and data from all units at the BHRS (including the channel sand), we can examine causes for the short-range periodicity in the level 1 horizontal experimental variogram such as the hole at $\sim 5 \mathrm{~m}$ lag (Figure 6a). The level 1 horizontal experimental variogram includes individual- and combined-unit structures for level 2 layered units (Units 1, 2, 3, and 5) and for patchy level 3 subunits in Unit 4 (Figure 14a). In this analysis, Units 1 and 3 are treated separately to allow for greater definition of causes for variogram features. These seven units and subunits result in 28 possible component variograms, but eight do not have horizontal pairings. Of the remaining 20 , five are primary contributors to the prominent hole at $\sim 5 \mathrm{~m}$ lag (Figure 14b). Of these five weighted component structures, four are combined-unit structures that include one or two subunits at hierarchical level 3 , and the fifth is the individual structure for Unit 2.

[46] Observation of the unweighted variograms for the component structures (Figure 14c) shows that: (1) periodicity is prominent in combined-unit structures $4 \mathrm{~A}-5$ and $4 \mathrm{~B}-5$ with holes at $\sim 5 \mathrm{~m} \mathrm{lag}$, and also at $\sim 8 \mathrm{~m}$ and $\sim 11 \mathrm{~m}$ lags; (2) periodicity is somewhat evident in combined-unit structures $4 \mathrm{~A}-4 \mathrm{C}$ and $3-4 \mathrm{C}$ at $\sim 4-6 \mathrm{~m}, \sim 8 \mathrm{~m}$, and $\sim 11-$ $12 \mathrm{~m}$ lags; and (3) periodicity is not evident in the individual-unit structure for Unit 2. However, weights (Figure 14d) are low for combined-unit structures, but the weight for the Unit 2 structure is largest of all and has a significant decrease in magnitude at $\sim 5 \mathrm{~m}$ lag (Figure 14b). Cross-sections of porosity logs and unit interpretations from porosity logs (Figures 4a, 4b, and 15) show: (1) patchy distribution of subunits in Unit 4 between wells; (2) pairings of these subunits with Unit 5 which cuts into Unit 4 toward 
A
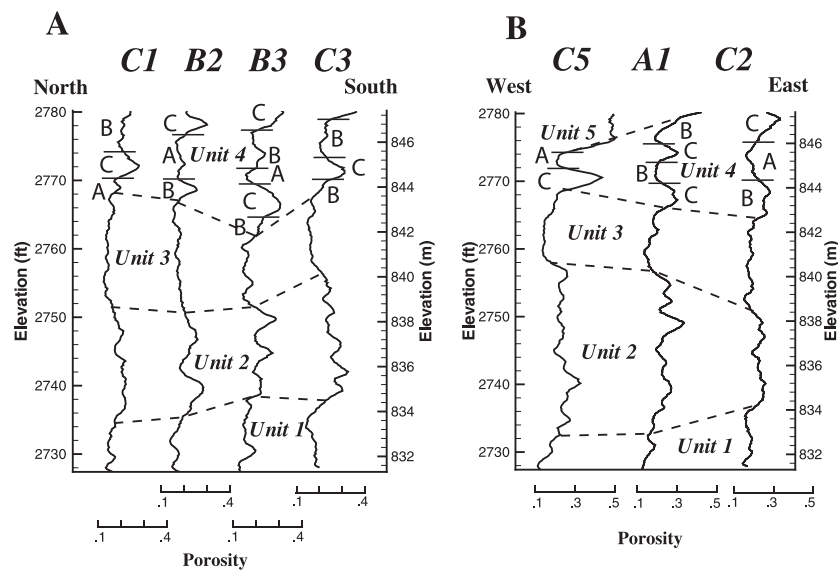

Figure 15. Cross sections of porosity logs (from Figures $4 \mathrm{a}$ and $4 \mathrm{~b}$ ) with interpreted subunits in Unit 4 added. Note general lack of lateral continuity of a given subunit between wells and relief on the surfaces of Unit 2. These features are consistent with the importance of combined and individual weighted variograms in determining shortrange global variogram spatial behavior. Relative lateral positions and horizontal scale for wells are given in inset of Figure 1.

the center of the site from the west; (3) pairings of these subunits with undulations in the upper surface of Unit 3; and (4) sufficient relief on the surfaces of Unit 2 to cause decreased relative numbers of data pairs at $\sim 5 \mathrm{~m}$ lag.

[47] In an outcrop or quarry study, it might be obvious from direct observation which sedimentary facies cause periodic structure. However, combined-facies structures are rarely considered and, in subsurface deposits with ambiguous information from core, one might be tempted to ignore small-scale structure as noise. Variogram decomposition provides the opportunity to examine component structures to see if a geological explanation for experimental variogram features is supported, even where sampling distribution may be less than ideal. From such an analysis above, it is clear that the features causing the hole at $\sim 5 \mathrm{~m}$ lag are primarily limited to subunits in Unit 4 and the surfaces of Unit 2 (Figures 14 and 15) and, thus, that the level 1 horizontal experimental variogram is a poor representation of the horizontal spatial variation of porosity through the full stratigraphic extent of the coarse fluvial deposits at the BHRS.

\subsubsection{Modeling Hierarchical Multifacies Systems}

[48] For multifacies systems with sparse data coverage, it is possible that $c_{i j}$ and $\gamma_{i j}(h)$ could be determined or estimated for all the individual facies and resulting combined facies so that the unknowns in equation (10) would be reduced to $\omega_{x_{a} i j}(h)$. Approaches to estimating $\omega_{x_{a} i j}(h)$ might include use of transition probability/Markov information [e.g., Tjelmeland and Holden, 1992; Carle et al., 1998] or stochastic modeling based on known facies volume proportions and shape distributions [e.g., Brannan and Haselow, 1993; Jussel et al., 1994]. If a system is recognized as hierarchical, for groundwater flow and transport modeling it would be more accurate to build the model structure based on level 2 facies, with known geostatistics incorporated for each level 2 facies, rather than to base the model on realizations using nonstationary level 1 geostatistics [Deutsch and Journel, 1992; Anderson, 1997]. If the distribution of level 2 facies cannot be determined in detail but the global site-specific level 1 geostatistics can be defined empirically, then it may be advantageous to constrain stochastic realizations of the distribution of level 2 units by comparing the level 1 geostatistics of the realizations with the experimental level 1 variogram. Poeter and McKenna [1995] demonstrated the value of such constraints for removing unacceptable models from the universe of possible (i.e., statistically equally probable) solutions to a given flow and transport problem.

\section{Summary and Conclusions}

[49] 1. The fluvial aquifer at the Boise Hydrogeophysical Research Site (BHRS) is a hierarchical sedimentary system with: (1) sitewide coarse-grained fluvial deposits at hierarchical level 1; (2) layered units at hierarchical level 2; and (3) lenses or subunits at hierarchical level 3 within one level 2 cobble-dominated unit.

[50] 2. Porosity geostatistics of hierarchical level 1 are best modeled as different horizontal and vertical structures with different horizontal and vertical sills. Level 1 geostatistics are nonstationary because the means and variances of porosity differences as a function of lag are not constant between distinct regions (i.e., level 2 units).

[51] 3. Porosity statistics and geostatistics of the five level 2 units in the central area of the BHRS indicate that: (1) three cobble-dominated units have transition-type vertical geostatistical structure with ranges of $\sim 1$ to $1.4 \mathrm{~m}$, but have uncertain horizontal structure; (2) the fourth cobbledominated unit has periodic vertical structure and is comprised of three subunits at hierarchical level 3; and (3) the fifth level 2 unit is a sand channel with indeterminate geostatistics due to data limitations. Cobble-dominated Units 1 and 3 have similar pdfs and geostatistical structures and are interpreted to be the same type of facies.

[52] 4. Quantitative description of vertical geostatistics of multifacies layered systems includes combined-layer structures in addition to structures of individual layers, and includes volume-fraction weighting of all individualand combined-layer contributions to the global structure as a function of lag.

[53] 5. A logical extension of the expression for the vertical variogram for a level 1 layered system leads to a general expression for the variogram of a hierarchical system at a given scale (e.g., level 1) with either stationary or nonstationary distributions of smaller scale units (e.g., level 2 units, level 3 subunits) in any direction.

[54] 6. Decomposition of a variogram of a given scale in a hierarchical system into component smaller scale individualand combined-facies variograms can provide information on the cause(s) for features such as holes in the large-scale variogram.

[55] 7. The level 1 horizontal experimental variogram for the BHRS is a poor representation of the horizontal spatial variability of porosity through the full stratigraphic extent of the coarse fluvial deposits.

[56] 8. If a system is recognized as hierarchical, for groundwater flow and transport modeling it would be more accurate to build the model structure based on level 2 facies, with known geostatistics incorporated for each level 2 
facies, rather than to base the model on realizations using nonstationary level 1 geostatistics.

[57] Acknowledgments. This project is supported by U.S. Army Research Office grant DAAH04-96-1-0318. Cooperative arrangements with the Idaho Transportation Department, the U.S. Bureau of Reclamation, and Ada County allow development and use of the BHRS and are gratefully acknowledged. J.M. Davis generously provided code he developed for generating jackknife confidence limits on experimental variograms in two dimensions; this code was adapted to three dimensions for work presented here. Also, we thank G. Fogg, R. Knight, K. Parks, and R. Ritzi whose review comments resulted in an improved manuscript. Contribution 0101 of the Center for Geophysical Investigation of the Shallow Subsurface at Boise State University.

\section{References}

Allen-King, R. M., R. M. Halket, D. R. Gaylord, and M. J. L. Robin, Characterizing the heterogeneity and correlation of perchloroethene sorption and hydraulic conductivity using a facies-based approach, Water Resour. Res., 34(3), 385-396, 1998.

Anderson, M. P., Hydrogeologic facies models to delineate large-scale spatial trends in glacial and glaciofluvial sediments, Geol. Soc. Am. Bull., 101(4), 501-511, 1989

Anderson, M. P., Characterization of geological heterogeneity, in Subsurface Flow and Transport: A Stochastic Approach, UNESCO Int. Hydr. Ser., edited by G. Dagan and S. P. Neuman, pp. 23-43, Cambridge Univ. Press, New York, 1997.

Armstrong, M., Improving the estimation and modelling of the variogram, in Geostatistics for Natural Resources Characterization, Part 1, edited by G. Verly et al., pp. 1-19, D. Reidel, Norwell, Mass., 1984.

Asprion, U., and T. Aigner, Aquifer architecture analysis using groundpenetrating radar: Triassic and Quaternary examples (S. Germany), Environ. Geol., 31, 66-75, 1997.

Atkins, J. E., and E. F. McBride, Porosity and packing of Holocene river, dune, and beach sands, AAPG Bull., 76(3), 339-355, 1992.

Barrash, W., and T. Clemo, Hierarchical geostatistics of porosity derived from neutron logs at the Boise Hydrogeophysical Research Site, Boise, Idaho, in Proceedings of TraM'2000, Liege, Belgium, May 23-26, 2000, IAHS Publ. 262, pp. 333-338, 2000.

Barrash, W., and M. D. Knoll, Design of research wellfield for calibrating geophysical measurements against hydrologic parameters, in 1998 Conference on Hazardous Waste Research, Snowbird, Utah, pp. 296-318, Great Plains/Rocky Mountains Hazard. Substance Res. Cent., Kans. State Univ., 1998

Barrash, W., and R. H. Morin, Recognition of units in coarse, unconsolidated braided-stream deposits from geophysical log data with principal components analysis, Geology, 25, 687-690, 1997.

Barrash, W., R. Morin, and D. M. Gallegos, Lithologic, hydrologic and petrophysical characterization of a coarse-grained, unconsolidated aquifer, Capital Station site, Boise, Idaho, in 32nd Symposium on Engineering Geology and Geotechnical Engineering, pp. 307-323, Boise, Idaho, March 26-28, 1997.

Barrash, W., T. Clemo, and M. D. Knoll, Boise Hydrogeophysical Research Site (BHRS): Objectives, design, initial geostatistical results, in SAGEEP '99. Symposium on the Application of Geophysics to Engineering and Environmental Problems, Oakland, Calif., pp. 389-398, 1999.

Beres, M., P. Huggenberger, A. G. Green, and H. Horstmeyer, Using twoand three-dimensional georadar methods to characterize glaciofluvial architecture, Sediment. Geol., 129, 1-24, 1999.

Bluck, B. J., Structure of coarse grained braided stream alluvium, Trans. $R$. Soc. Edinburgh, 70, 181-221, 1979.

Brannan, J. R., and J. S. Haselow, Compound random field models of multiple scale hydraulic conductivity, Water Resour. Res., 29(2), 365372, 1993.

Carle, S. F., E. M. Labolle, G. S. Weissmann, D. van Brocklin, and G. E. Fogg, Conditional simulation of hydrofacies architecture: A transition probability/Markov approach, in Hydrogeologic Models of Sedimentary Aquifers, SEPM Concepts in Hydrogeology and Environmental Geology 1, edited by G. S. Fraser and J. M. Davis, pp. 147-170, Tulsa, Okla., 1998.

Clement, W. P., M. D. Knoll, L. M. Liberty, P. R. Donaldson, P. Michaels, W. Barrash, and J. R. Pelton, Geophysical surveys across the Boise Hydrogeophysical Research Site to determine geophysical parameters of a shallow, alluvial aquifer, in SAGEEP '99, Symposium on the Application of Geophysics to Engineering and Environmental Problems, Oakland, Calif., pp. 399-408, 1999.

Cressie, N., and D. Hawkins, Robust estimation of the variogram, Math. Geol., 12(2), 115-125, 1980.

Davis, J. M., R. C. Lohmann, F. M. Phillips, J. L. Wilson, and D. W. Love, Architecture of the Sierra Ladrones Formation, central New Mexico Depositional controls on the permeability correlation structure, Geol. Soc. Am. Bull., 105(8), 998-1007, 1993.

Davis, J. M, J. L. Wilson, F. M. Phillips, and M. Gotkowitz, Relationship between fluvial bounding surfaces and permeability correlation structure, Water Resour. Res., 33(8), 1843-1854, 1997.

Daws, J. A., and D. J. Prosser, Scales of permeability heterogeneity within the Brent Group, J. Pet. Geol., 15(4), 397-418, 1992.

Deutsch, C. V., and A. G. Journel, GSLIB Geostatistical Software Library and User's Guide, 340 pp., Oxford Univ. Press, New York, 1992.

Dowd, P. A., The variogram and kriging: Robust and resistant estimators, in Geostatistics for Natural Resources Characterization, Part 1, edited by G. Verly et al., D. Reidel, Norwell, Mass., pp. 91-106, 1984

Fogg, G. E., C. D. Noyes, and S. F. Carle, Geologically based model of heterogeneous hydraulic conductivity in an alluvial setting, Hydrogeol. J., 6, 131-143, 1998

Goggin, D. J., M. A. Chandler, G. Kocurek, and L. W. Lake, Patterns of permeability in Eolian deposits: Page sandstone (Jurassic), northeastern Arizona, SPE Form. Eval., 3, 297-306, 1988.

Hearst, J. R., and P. H. Nelson, Well Logging for Physical Properties, 571 pp., McGraw-Hill, New York, 1985.

Hubbard, S. S., Y. Rubin, and E. Majer, Spatial correlation structure estimation using geophysical and hydrogeological data, Water Resour. Res., 35(6), 1809-1825, 1999.

Huggenberger, P., Radar facies: Recognition of facies patterns and heterogeneities within Pleistocene Rhine gravels, NE Switzerland, in Braided Rivers, Geol. Soc. Spec. Publ. 75, edited by C. S. Bristow and J. L. Best, pp. $163-176,1993$.

Huggenberger, P. E., E. Meier, and A. Pugin, Ground-probing radar as a tool for heterogeneity estimation in gravel deposits: Advances in data processing and facies analysis, J. Appl. Geophys., 31, 171-184, 1994.

Hyndman, D. W., and S. M. Gorelick, Estimating lithologic and transport properties in three dimensions using seismic and tracer data, Kesterson aquifer, Water Resour. Res., 32(9), 2659-2670, 1996.

Indelman, P., G. Moltanyer, and G. Dagan, Determining the hydraulic conductivity spatial structure at the Twin Lake site by grain-size distribution, Ground Water, 37(2), 223-227, 1999.

Jensen, J. J., P. W. Corbett, G. E. Pickup, and P. S. Ringrose, Permeability semivariograms, geological structure, and flow performance, Math. Geol., 28(4), 419-435, 1996.

Journel, A. G., and C. J. Huijbregts, Mining Geostatistics, 600 pp., Academic Press, San Diego, Calif., 1978.

Jussel, P., Stochastic description of typical inhomogeneities of hydraulic conductivity in fluvial gravel deposits, in Contaminant Transport in Groundwater, Proceedings of the International Symposium on Contaminant Transport in Groundwater, Stuttgart, April 4-6, 1989, edited by E. H. Kobus and W. Kinzelbach, pp. 221-228, IAHR, 1989.

Jussel, P., F. Stauffer, and T. Dracos, Transport modeling in heterogeneous aquifers, 1, Statistical description and numerical generation, Water Resour. Res., 30(6), 1803-1817, 1994.

Knoll, M., and W. Clement, Vertical radar profiling to determine dielectric constant, water content and porosity values at well locations, in SAGEEP '99, Symposium on the Application of Geophysics to Engineering and Environmental Problems, Oakland, Calif., pp. 821-830, 1999.

Koltermann, C. E., and S. M. Gorelick, Fractional packing model for hydraulic conductivity derived from sediment mixtures, Water Resour. Res. 31(12), 3283-3297, 1995.

Koltermann, C. E., and S. M. Gorelick, Heterogeneity in sedimentary deposits: A review of structure-imitating, process-imitating, and descriptive approaches, Water Resour. Res., 32(9), 2617-2658, 1996.

Kupfersberger, H., and C. V. Deutsch, Methodology for integrating analog geologic data in 3-D variogram modeling, AAPG Bull., 83(8), 1262$1278,1999$.

McKenna, S. A., and E. P. Poeter, Field example of data fusion in site characterization, Water Resour. Res., 31(12), 3229-3240, 1995

Miall, A. D., Architectural-element analysis: A new method of facies analysis applied to fluvial deposits, Earth Sci. Rev., 22, 261-308, 1985.

Milliken, G. A., and D. E. Johnson, Analysis of Messy Data, vol. I, Designed Experiments, Chapman and Hall, New York, 1992.

Morin, R. H., D. R. LeBlanc, and W. E. Teasdale, A statistical evaluation of 
formation disturbance produced by well-casing installation methods, Ground Water, 26, 207-217, 1988.

National Institute of Standards and Technology (NIST), NLSW Module in Starpac, Guide to Available Math Software, retrieved from CAMSUN, 1998.

Peretti, W. R., M. D. Knoll, W. P. Clement, and W. Barrash, 3-D GPR imaging of complex fluvial stratigraphy at the Boise Hydrogeophysical Research Site, in Proceedings of SAGEEP '99, Symposium on the Application of Geophysics to Engineering and Environmental Problems, March 14-18, 1999, Oakland, Calif., pp. 555-564, 1999.

Pettijohn, F., P. Potter, and R. Siever, Sand and Sandstone, 618 pp., Springer-Verlag, New York, 1973

Poeter, E., and D. R. Gaylord, Influence of aquifer heterogeneity on contaminant transport at the Hanford site, Ground Water, 28(6), 900-909 1990.

Poeter, E. P., and S. A. McKenna, Reducing uncertainty associated with ground-water flow and transport predictions, Ground Water, 33(6), 899904, 1995.

Prosser, D. J., M. E. McKeever, A. J. C. Hogg, and A. Hurst, Permeability heterogeneity within massive Jurassic submarine fan sandstones from the Miller Field, northern North Sea, UK, in Characterization of Deep Marine Clastic Systems, Geol. Soc. Spec. Publ. 94, edited by A. J. Hartley and D. J. Prosser, pp. 201-219, Geol. Soc., London, 1995.

Rea, J., and R. Knight, Geostatistical analysis of ground-penetrating radar data: A means of describing spatial variation in the subsurface, Water Resour. Res., 34(3), 329-339, 1998.

Reboulet, E. C., and W. Barrash, Identification of hydrostratigraphic facies in coarse, unconsolidated, braided-stream deposits at the Boise Hydrogeophysical Research Site (abstract), Geol. Soc. Am. Annu. Meet., Oct. 25-29, 1999, Denver, Colo., Abstr. Programs Geol. Soc. Am., 31(7) A350, 1999.

Reboulet, E. C., and W. Barrash, Statistical analysis of grain-size distribu- tion and porosity data from coarse braided-stream deposits at the Boise Hydrogeophysical Research Site (abstract), Geol. Soc. Am. Annu. Meet., Reno, Nev., Nov. 13-16, 2000, Abstr. Programs Geol. Soc. Am., 32(7), A410, 2000.

Regli, C., P. Huggenberger, and M. Rauber, Interpretation of drill core, and georadar data of coarse gravel deposits, J. Hydrol., 255, 234-252, 2002.

Rehfeldt, K. R., J. M. Boggs, and L. W. Gelhar, Field study of dispersion in a heterogeneous aquifer, 3, Geostatistical analysis of hydraulic conductivity, Water Resour. Res., 28(12), 3309-3324, 1992.

Rubin, Y., Flow and transport in bimodal heterogeneous formations, Water Resour. Res., 31(10), 2461-2468, 1995.

Shafer, J. M., and M. Varljen, Approximation of confidence limits on sample semivariograms from single realizations of spatially correlated random fields, Water Resour. Res., 26, 1787-1802, 1990.

Smith, N. D., Proglacial fluvial environment, in Glacial Sedimentary Environments, SEPM Short Course 19, edited by G. M. Ashley, J. Shaw, and N. D. Smith, chap. 3, pp. 85-134, Soc. of Econ. Paleontol. and Mineral., Tulsa, Okla., 1985.

Tjelmeland, H., and L. Holden, Semi-Markov random fields, in Geostatis tics Troia '92, vol. 1, edited by A. Soares, pp. 479-491, Kluwer Acad., Norwell, Mass., 1992.

Webb, E. K., and M. P. Anderson, Simulation of preferential flow in threedimensional, heterogeneous conductivity fields with realistic internal architecture, Water Resour. Res., 32(3), 533-545, 1996.

Woodbury, A. D., and E. A. Sudicky, The geostatistical characterization of the Borden aquifer, Water Resour. Res., 27(4), 533-546, 1991.

T. Clemo and W. Barrash, Center for Geophysical Investigation of the Shallow Subsurface and Department of Geosciences, Boise State University, Boise, ID 83725, USA. (wb@cgiss.boisestate.edu) 